FEDERAL RESERVE BANK OF SAN FRANCISCO

WORKING PAPER SERIES

\title{
Medicaid Expansion and the Unemployed
}

\author{
Thomas C. Buchmueller \\ University of Michigan; \\ Helen Levy \\ University of Michigan \\ Robert G. Valletta \\ Federal Reserve Bank of San Francisco
}

December 2019

Working Paper 2019-29

https://www.frbsf.org/economic-research/publications/working-papers/2019/29/

\section{Suggested citation:}

Buchmueller, Thomas C., Helen Levy, Robert G. Valletta. 2019. "Medicaid Expansion and the Unemployed,” Federal Reserve Bank of San Francisco Working Paper 2019-29.

https://doi.org/10.24148/wp2019-29

The views in this paper are solely the responsibility of the authors and should not be interpreted as reflecting the views of the Federal Reserve Bank of San Francisco or the Board of Governors of the Federal Reserve System. 


\title{
Medicaid Expansion and the Unemployed
}

\author{
Thomas C. Buchmueller \\ Ross School of Business \\ University of Michigan \\ tbuch@umich.edu \\ Helen Levy \\ Institute for Social Research \\ University of Michigan \\ hlevy@umich.edu \\ Robert G. Valletta \\ Federal Reserve Bank of San Francisco \\ rob.valletta@sf.frb.org
}

\section{November 2019}

\begin{abstract}
We examine how a key provision of the Affordable Care Act - the expansion of Medicaid eligibility — affected health insurance coverage, access to care, and labor market transitions of unemployed workers. Comparing trends in states that implemented the Medicaid expansion to those that did not, we find that the ACA Medicaid expansion substantially increased insurance coverage and improved access to health care among unemployed workers. We then test whether this strengthening of the safety net affected transitions from unemployment to employment or out of the labor force. We find no meaningful statistical evidence in support of moral hazard effects that reduce job finding or labor force attachment.
\end{abstract}

Keywords: Medicaid, insurance coverage, access to care, unemployment, labor force transitions JEL codes: J64, J68, I13, I18

Acknowledgements/disclaimer: Prepared for presentation at "Defense against the Dark Arts: A labor economics conference in honor of John E. DiNardo," University of Michigan, September 28-29, 2018. Financial support for this project from the Russell Sage Foundation is gratefully acknowledged. The views expressed in this paper are solely those of the authors and are not attributable to the Federal Reserve Bank of San Francisco or the Federal Reserve System. 


\section{Introduction}

Job loss can be a catastrophic event for workers and their families. The Unemployment Insurance (UI) program provides partial income replacement for some job losers, but UI does not fully smooth consumption shocks associated with job loss (Gruber 1997; Browning and Crossley 2009). Job loss also leaves households at risk of a range of negative outcomes. In the short run, these include reduced income and difficulty finding new work (Farber 2017), loss of health insurance (Schaller and Stevens 2015; Jolly and Phelan 2017), and increased debt (Sullivan 2008). In the longer run, potential consequences include depleted savings and postponed retirement (Chan and Stevens 1999), increased risk of mortality (Sullivan and von Wachter 2009), and adverse effects on children's well-being (Kalil and Wightman 2011).

The Affordable Care Act (ACA) may have mitigated one consequence of unemployment by creating new, subsidized health insurance options for individuals lacking access to employersponsored coverage. This development is noteworthy at a time when the prevailing trend is to shift work-related risks from employers and government to workers and their families (Hacker 2006; Morduch and Schneider 2017). Examples of this trend include the rise of contingent work (Katz and Krueger 2016) and the shift from defined benefit to defined contribution retirement plans. The ACA represents a rare movement in the other direction: an expansion of the safety net (Buchmueller and Valletta 2017).

Expanding the safety net and reducing exposure to risk may entail moral hazard. In the context of unemployment, economists have long noted that UI, by softening the downside of unemployment, likely increases the duration of unemployment spells (see, for example, Baily 1978; Krueger and Meyer 2002; Chetty 2008; Rothstein 2011; Farber and Valletta 2015; or Farber, Rothstein, and Valletta 2015). Expanding access to health insurance for the unemployed may have a similar effect. For example, Gruber and Madrian (1997) found that continuation-of- 
coverage mandates for private coverage - that is, state laws requiring employers to offer what is now commonly known as COBRA coverage — increased the number of months workers spent not employed, although at least some of this was productive search resulting in higher reemployment wages. Existing evidence on the effect of Medicaid on labor supply is mixed, as we discuss in detail below. Nonetheless, eleven states are in the process of imposing work requirements on Medicaid recipients out of concern that eligibility expansions might otherwise reduce labor supply (Garfield et al. 2018).

In this paper we explore the implications of the ACA Medicaid expansion for unemployed workers. Our general empirical strategy is a difference-in-differences approach that compares outcomes for workers in states that implemented the Medicaid expansions and those in states that did not. We begin by testing for an effect of the expansion on the insurance coverage of unemployed workers using data from the American Community Survey (ACS) for the years 2008 to 2017. Prior to 2014, when the main coverage provisions of the ACA went into effect, unemployed workers were roughly three times as likely to be uninsured as employed workers. From 2008 to 2013 the percentage of unemployed and employed workers without insurance, as well as the percent with Medicaid or different forms of private insurance, were trending in a similar fashion in states that eventually chose to expand Medicaid under the ACA and those that did not. After 2014, insurance coverage increased in both groups of states; the change was roughly twice as large for unemployed workers in expansion states than for those in nonexpansion states. In expansion states, the fraction of unemployed workers without health insurance was cut in half. We also find some evidence in data from the 2008 through 2017 Behavioral Risk Factor Surveillance Survey (BRFSS) that access to medical care improved more for the unemployed in expansion states than in non-expansion states. 
The insurance coverage and access to care results provide strong evidence that the ACA Medicaid expansion substantially strengthened the safety net for unemployed workers in states that implemented it. We next consider whether this greater access to health insurance affected job search behavior, as reflected in the rates of transitions out of unemployment. Using basic monthly Current Population Survey (CPS) data on unemployed individuals matched across consecutive CPS survey months for the period 2007 through 2017, we estimate models similar to those used to study the effect of extended unemployment insurance benefits, distinguishing between unemployment exits to employment and out of the labor force. Our difference-indifferences regression tests show no evidence of moral hazard - that is, no statistically meaningful reduction in job-finding rates or labor force attachment in Medicaid expansion states relative to non-expansion states after expansion occurred. To the contrary, we find that Medicaid expansion reduced labor force exits for some groups (parents and the short-term unemployed), indicating modest positive effects on labor force attachment.

As we discuss in more detail in Section VII, this null result for job-finding may be explained by the in-kind nature of Medicaid combined with the tendency for uninsured households to have low health expenditures even when they use care. Thus, there is little scope for Medicaid expansion to ease household budgets enough for an unemployed family member to reduce job search intensity or decline job offers as a result.

\section{Background and Previous Literature}

\section{A. The Safety Net, Job Search, and Employment}

Safety net programs are aimed at insuring against economic loss and maintaining living standards at an acceptable level. This entails the potential downside of adverse incentive effects 
on related economic behaviors and outcomes. Optimal social insurance therefore balances such "moral hazard" effects against consumption smoothing or other welfare benefits of the policy (Bailey 1978; Chetty 2006).

Past work on optimal social insurance has focused primarily on UI, which relates directly to recipients' labor market status and hence has significant and readily observable moral hazard effects. In particular, the increase in reservation wages prompted by UI income may reduce job search intensity and the propensity to accept job offers. UI benefits generally are available for 26 weeks in the United States, but availability typically is extended during periods of economic distress. Much of the existing research that assesses the impacts of unemployment benefits on search behavior focuses on benefit generosity (weekly/monthly payment amounts), which follows directly from the role of reservation wages in the underlying theory of optimal UI (e.g., Moffitt 1985, Solon 1985, Meyer 1990). Other studies that focused on benefit duration found that an increase in the maximum duration of benefits leads to an increase in average UI spell durations (notably Moffitt 1985, Katz and Meyer 1990, Card and Levine 2000, Jurajda and Tannery 2003, and Schwartz 2013).

A new generation of this literature emerged after the Great Recession of 2007-09, when UI benefits were extended to an historically unprecedented maximum of 99 weeks. Despite the large expansion of available benefit durations, papers that examined search responses to the benefit expansions generally found relatively small effects on overall unemployment transitions and durations (e.g., Rothstein 2011; Farber and Valletta 2015; Farber, Rothstein, and Valletta 2015; Valletta 2014). Moreover, most of the impact of the benefit extensions took the form of a reduced tendency to exit the labor force-i.e., prolonged job search—rather than a reduction in the rate of job finding. This finding was enabled by reliance on CPS survey data (matched across 
adjacent months) that distinguished between different exit routes from unemployment, as we use later in this paper. The results from these papers suggest more limited moral hazard effects of extended UI than did the earlier generation of research. ${ }^{1}$

The relevance of this literature in our setting is heightened by the abrupt withdrawal of extended benefit availability at the end of 2013 , due to a congressional decision not to renew the 2008 Emergency Unemployment Compensation (EUC) program at that time. The effect of this abrupt loss of extended UI benefits corresponds exactly to when the ACA Medicaid expansions first took effect (in January of 2014). The reduction in UI availability could offset and hence bias the estimated impact of the expansion of Medicaid availability. This emphasizes the importance of incorporating data on UI availability and the staggered timing of Medicaid expansion into our analyses. We discuss our approach to this issue further in Sections V and VI.

\section{B. Medicaid and Labor Supply: Pre-ACA Evidence}

Other safety net programs are less directly tied to employment and job search status than is UI, but they nonetheless may have moral hazard effects of their own. Most safety net programs are means-tested, requiring that income not exceed a specified threshold, and as such they may reduce work incentives in general. The resulting reduction in labor supply can occur along the intensive (hours) or extensive (participation) margins. The specific effects will depend on the exact structure of any given program, in particular its own and family income thresholds, work and job search requirements, etc. Disability insurance has been found to have substantial work

\footnotetext{
${ }^{1}$ This finding is consistent with other research suggesting that moral hazard effects of UI on job search are largely offset by the favorable liquidity and social insurance effects (Chetty 2008; Card, Chetty, and Weber 2007; Landais 2015). This may reflect reduced effects of UI on job search when labor market conditions are especially weak, although the evidence on this point is mixed (see the discussion in section 2.2 of Valletta 2014). Other recent research using UI administrative data finds evidence of larger moral hazard effects (Card et al. 2015; Johnston and Mas 2018). We discuss these issues further in Section VII.
} 
disincentive effects. ${ }^{2}$ These occur primarily along the labor force participation margin, since program eligibility requires strong evidence of inability to work.

Medicaid is another example of a means-tested program that may create a disincentive to work and hence affect labor supply and job attachment. Research on the relationship between Medicaid and labor supply in the years prior to the ACA has produced mixed results (for a review, see Buchmueller, Ham and Shore-Sheppard (2016); more recent additions to this literature include Pohl (2018) and Bradley and Sabik (2019)). Because very few non-disabled childless adults were eligible for Medicaid prior to the ACA, most of this research focuses on low-income parents. Several studies, however, analyzed the experiences of individual states that changed eligibility for non-disabled, childless adults. Garthwaite, Gross and Notowidigdo (2014) examine the effect of a major contraction of Medicaid eligibility in Tennessee. Their analysis of data from the March CPS suggests that the loss of Medicaid coverage led to large increases in employment and private health insurance coverage. However, these results for Tennessee are not evident in other data sources (DeLeire 2018; Ham and Ueda 2017). Dague, DeLeire, and Leininger (2017) analyze the impact of a Medicaid enrollment cap in Wisconsin for nondisabled, childless adults, finding that program enrollment is associated with a significant reduction in employment. In contrast, Baicker et al. (2014), using administrative data from the Social Security Administration linked to participants in the Oregon Health Insurance Experiment, find no significant effect of Medicaid on earnings or employment.

\footnotetext{
${ }^{2}$ See Abraham and Kearney (2018) for a broad summary of this literature.
} 


\section{The ACA and its Effect on Insurance Coverage and Labor Supply}

The ACA included provisions to expand both public and private health insurance. As it was originally enacted in 2010, the law would have required all states to expand their Medicaid programs to cover all individuals ages 19 through 64 in families with incomes below 138 percent of the Federal Poverty Level (FPL) beginning January 1, 2014. However, a Supreme Court decision in 2012 allowed states to opt out of Medicaid expansion altogether.

Table 1 summarizes state Medicaid expansion decisions and how we categorize states for our analysis. Twenty-four states plus the District of Columbia chose to implement the ACA expansion on or before January 1, 2014. Six states took advantage of a provision in the law allowing them to begin expanding earlier, either shifting enrollees from state-funded programs into Medicaid, gradually raising eligibility limits, or rolling out the new eligibility standard incrementally by county. Overall, the coverage increases before 2014 in these early expansion states were limited (Sommers et al. 2014). Moreover, all early expansion states experienced significant coverage increases between 2013 and 2014. In light of these results, in our main analysis we group the six early expansion states with the 18 states that implemented the expansion in January 2014. (As a robustness check, we estimate models dropping these early expansions states.) Seven states expanded later (2 in 2014, 3 in 2015 and 2 in 2016); most of which expanded in the middle of the year and are coded, in our analyses relying annual data, as having expanded coverage for the entire year. In our analyses of monthly data from the CPS mid-year expanders are coded as having expanded coverage during the month in which they did so. As of October 2019, five additional states - Maine, Virginia, Nebraska, Idaho, and Utah are in the process of implementing expansion, but are considered non-expansion states for our 
purposes because our data extend only through 2017. The remaining 14 states have not begun to expand their Medicaid programs. ${ }^{3}$

The ACA also implemented private insurance market reforms beginning in January 2014, such as prohibiting plans from denying coverage based on an applicant's health status. It established new health insurance marketplaces, sometimes called "exchanges," to facilitate shopping for individual coverage by providing a website where enrollees could easily compare their plan options. Importantly, the law provides premium tax credits for families with income between 100 and 400 percent of poverty to purchase coverage through the marketplaces, provided that they do not already have access to Medicaid or coverage through an employer. Tax credits are calculated on a sliding scale, with the family's share of the premium capped at between 2 and 9.5 percent of family income. Premiums for marketplace plans cannot vary based on health status, and the law limits allowable variation based on age, so that older enrollees cannot be required to pay more than three times what a younger enrollee would be charged for the same plan.

It is estimated that nearly 20 million Americans gained health insurance coverage as a result of the ACA (Courtemanche et al. 2017; Blumberg, Garrett, and Holahan 2016). Between 2013 and 2016, coverage increased for all age groups (under age 65) and in every U.S. state (Barnett and Berchick 2017). Numerous studies have examined the effect of the Medicaid

\footnotetext{
${ }^{3}$ The non-expansion group includes Wisconsin, which prior to the ACA had a public insurance program, BadgerCare, which provided coverage to parents with incomes up to 200 percent of the FPL. In 2014, Wisconsin reduced the income eligibility limit for parents to 100 percent of the FPL and extended BadgerCare eligibility to childless adults, who had been categorically ineligible. This makes Wisconsin unique among states that rejected the ACA Medicaid expansion in that there is no "coverage gap" for adults with incomes below the poverty line. Between 2013 and 2014, the percent uninsured in Wisconsin fell by 1.8 percentage points, which is slightly less than the 2.3 percentage point decline observed in all non-expansion states (Smith and Medalia 2015).
} 
expansion (see Antonisse et al (2018) for a comprehensive review). A general finding is that coverage increased more in states that implemented the Medicaid expansion than in states that did not, especially among low-income adults (Sommers et al 2015; Wherry and Miller 2016; Miller and Wherry 2017), disadvantaged populations, such as racial and ethnic minorities (McMorrow et al 2015; Buchmueller et al 2016), and states or local areas with higher baseline rates of uninsurance (Courtemanche et al 2017; Duggan et al 2017). The effect of the Medicaid expansion on insurance coverage was especially large for childless adults (Kaestner et al 2017), who in most states were not eligible for Medicaid at all prior to 2014.

The effect of the ACA coverage expansions on labor supply incentives is complex. The increase in the Medicaid income eligibility threshold means that some individuals who were previously covered can work and earn more without losing coverage because they are no longer close to their state's eligibility cutoff. At the same time, workers who would have otherwise earned slightly more than the new eligibility limit of 138 FPL may reduce their hours to qualify for Medicaid. For individuals who gain Medicaid coverage as a result of the ACA, labor supply may also fall as a result of an income effect. Above the poverty level, the phase-out of meanstested subsidies for marketplace coverage increases the effective marginal tax rate on earnings, which has the potential to reduce labor supply. However, in non-expansion states, workers with incomes just below poverty have an incentive to work more (or report higher incomes (Kucko, Rinz and Solow (2018)) in order to qualify for premium tax credits.

In light of these theoretical considerations and a large literature finding significant effects of employer-sponsored insurance on job mobility, hours and retirement (see Gruber and Madrian (2002) for a review), the Congressional Budget Office projected that by 2024 the ACA would reduce aggregate hours worked by roughly 2 percent (Harris and Mok 2015). Several recent 
studies test for an immediate effect of the ACA Medicaid expansion on various measures of employment (Leung and Mas 2018; Gooptu et al 2016; Kaestner et al 2017; Duggan, Goda and Jackson 2017; Fang 2017; Frisvold and Jung 2018; Levy, Buchmueller and Nikpay 2016; Peng et al. 2018). Despite differences in the outcomes studied and research design choices, the results of the various studies are quite consistent, finding no significant effect on employment, hours, retirement or job mobility.

To date, there have been no studies focusing on how Medicaid expansion may have affected insurance coverage or re-employment among the unemployed. The unemployed represent a particularly interesting subgroup for this purpose, both because they had low rates of coverage to begin with and therefore stood to gain substantially from coverage expansions and also because re-employment decisions may be more elastic than, for example, a decision of how many hours to work for a worker who is already employed. In a nutshell: if anyone's labor market decisions were distorted by Medicaid expansion, it seems likely that it would have been the unemployed.

\section{Analysis, Part 1: Insurance Coverage of the Unemployed}

\section{A. Data and Descriptive Analysis}

Our analysis of health insurance coverage uses data from the ACS, which includes annual data on health insurance starting in 2008. Advantages of the ACS include consistent measurement of health insurance over time and a very large sample: approximately 3 million observations in all, including between 90,000 and 150,000 individuals in each year who are unemployed at the time of the survey. The ACS asks one question about health insurance: "Is this person CURRENTLY covered by any of the following types of health insurance or health 
coverage plans?" This question is followed by an 8 -item checklist. ${ }^{4} \mathrm{We}$ examine four insurancerelated outcomes of interest: uninsured, which is defined as having none of the sources of coverage listed; Medicaid or other public coverage; employer-sponsored private coverage (which would include both COBRA coverage through a former employer and coverage as a dependent on a spouse's policy); and non-group private coverage.

The ACA included a provision requiring insurers to allow parents with employersponsored insurance to cover their adult children as dependents up to age 26, beginning in September 2010. This provision led to a significant increase in insurance coverage among 19 to 25-year-olds (Sommers et al 2013; Akosa Antwi et al 2013, 2014; Barbaresco et al 2014). Studies examining the effect of the policy on labor market outcomes yield mixed results (Antwi, Moriya and Simon 2013; Heim, Lurie and Simon 2015; Coleman and Dave 2015; Bailey and Chorniy 2016). To isolate the effect of the 2014 Medicaid expansion from this earlier ACA provision, we limit our analysis sample to adults between the ages of 26 and 64 .

Table 2 presents pre-ACA data on the percent uninsured with additional breakdowns by worker demographic characteristics. These descriptive results indicate dramatic differences in insurance coverage between the employed and the unemployed. In 2008-2010, unemployed workers were roughly three times as likely to be uninsured as those who are employed: 56 vs. 18 percent in non-expansion states and 44 versus 14 percent in expansion states. ${ }^{5}$ As would be expected, this gap is driven by large differences in employer-sponsored coverage, which is partly

\footnotetext{
${ }^{4}$ The options are: (a) employer-sponsored insurance; (b) insurance purchased directly from an insurance company; (c) Medicare; (d) Medicaid or other public insurance; (e) TRICARE/military health care; (f) Veteran's Administration; (g) Indian Health Service; and (h) any other type of health plan. Respondents are coded as uninsured if they answer no to all of these options.

${ }^{5}$ Note that these unadjusted differences should not be interpreted as a causal effect of unemployment on insurance coverage. Research using recent longitudinal data suggests that job loss is associated with a decline in insurance coverage of between 10 and 13 percentage points (Gruber and Madrian 1997; Schaller and Stevens 2015).
} 
offset by higher rates of Medicaid coverage among the unemployed. Among both employed and unemployed workers, the probability of being uninsured declines with age and education. As a result, the employed/unemployed coverage gap is similar for older and younger workers and those with higher and lower levels of education. The story is different when we cut the data by parental status. Whereas parents and childless adults have similar coverage rates when employed, among the unemployed childless adults are substantially more likely to be uninsured.

Figure 1 presents unadjusted trends in four insurance coverage outcomes - Medicaid, private non-group coverage, employer-sponsored coverage, and uninsured - for unemployed and employed adults in expansion and non-expansion states. Note that for these figures, we drop data from the seven states that expanded Medicaid after January 2014, although data from these states is included in the trends presented in Appendix Table A1 and will be incorporated into our regression analyses below.

Prior to 2014, expansion and non-expansion states had similar rates of private coverage. Expansion states had higher rates of Medicaid coverage, which translated to a lower percent uninsured. All four types of coverage were trending in a similar fashion in expansion and nonexpansion states. For Medicaid, this changed substantially in 2014 when the ACA expansion went into effect. In expansion states, Medicaid coverage increased sharply between 2013 and 2017, by 20 percentage points among unemployed workers and 5 percentage points among employed individuals. In contrast, in non-expansion states there was no apparent break in trend for Medicaid coverage. Rates of non-group coverage were also quite stable prior to 2014 . Beginning in 2014, non-group coverage increased for unemployed workers in both groups of states, presumably reflecting the ACA programs implemented in every state, such as health 
insurance marketplaces and premium tax credits. Employer coverage, in contrast, shows no sharp break in trend in 2014.

The net effect of these trends is that the fraction uninsured dropped for all unemployed workers starting in 2014. The drop was much larger for unemployed workers in expansion states, who experienced a 22.8-percentage point drop in the percent uninsured between 2013 and 2017 (from 42.6 percent to 19.8 percent), compared with a drop of only 10.8 percentage points (from 54.9 percent to 44.1 percent) for unemployed individuals in non-expansion states. For employed workers, the percent uninsured fell by smaller amounts: 7 percentage points in expansion states and 5 percentage points in non-expansion states.

\section{B. Regression Analysis}

For a closer look at changes in coverage, we estimate two sets of regression analyses. The first set relies on a differences-in-differences (DD) specification of the following form:

$$
Y_{i s t}=\beta \cdot \text { treatment }_{s t}+\alpha_{s}+\gamma_{t}+X_{i s t}^{\prime} \theta+W_{s t}^{\prime} \pi+e_{s t}
$$

The model is estimated separately for the four binary health insurance outcomes described above: Medicaid coverage, private non-group coverage, employer coverage, and uninsured. The variable treatment st $_{\text {is }} 1$ for any observation in a state/year in which Medicaid expansion is in effect and is 0 otherwise. (This is analogous to the variable post $x$ treatment in a standard difference-in-differences framework, but accounts for the fact that expansion occurred at different times in different states.) The coefficient $\beta$ therefore measures the marginal effect of Medicaid expansion on the outcome. The model also includes a full set of state and year dummies ( $\alpha_{s}$ and $\gamma_{t}$, respectively). The vector $X_{i s t}$ consists of individual-level controls: age (five 
categories), education (five categories), race/ethnicity (five categories), and gender by marital status. The model also includes several state/year-level controls $\left(W_{s t}\right)$ : cubics in the unemployment rate and employment growth, and the annual average number of weeks of UI benefits available. The model is estimated as a linear probability model weighted by the ACS survey weights. Robust standard errors are clustered by state.

A key advantage of this specification is that the coefficient $\beta$ provides a concise estimate of the effect of the Medicaid expansions. This basic DD model has two limitations, however. First, it does not allow for a clear test of the critical parallel trends assumption. Second, it imposes the assumption that the full impact of Medicaid expansion is realized immediately and is the same over the post-implementation period; in fact, the effect may grow over time, as consumer understanding of their insurance options grows. Therefore, we also estimate a second, more flexible event history specification. In this model, the dummy treatmentst is replaced with a vector of dummies $D_{s t}^{k}$ indicating time relative to the year in which Medicaid expansion occurs:

$$
Y_{i s t}=\sum_{k=-7}^{4} \delta_{k} D_{s t}^{k}+\gamma_{t}+\alpha_{s}+X_{i s t}^{\prime} \theta+W_{s t}^{\prime} \pi+u_{i s t}
$$

The dummy $D^{0}$ - which for most expansion states is equal to one in 2013 - is omitted, so that all effects are being measured compared to the size of the expansion/non-expansion gap in the year just before the expansion took effect.

Table 3 reports the estimates of $\beta$ from equation (1) for all four insurance outcomes. Models were estimated separately for the unemployed (Panel A) and the employed (Panel B); 
each column contains results for a different subsample (low vs. high education, parent/nonparent, duration of unemployment). ${ }^{6}$

Overall, Medicaid expansion resulted in a 13-percentage point increase in Medicaid recipiency among the unemployed. As shown in Figure 1, non-group coverage increased in both expansion and non-expansion states, though more so in the latter. The explanation for this is that in expansion states individuals with incomes between 100 and 138 percent of the FPL are enrolled in Medicaid, whereas in non-expansion states they obtain subsidized private non-group coverage through the ACA Marketplace. This results in a DD coefficient of -0.025 for non-group coverage in the full unemployed sample. The point estimate for employer-sponsored coverage is also negative and of a similar magnitude, also because of a larger increase in non-expansion states. For unemployed workers, employer-sponsored coverage is likely through COBRA or a spouse's employer. ${ }^{7}$ Individuals in non-expansion states may have been induced by the ACA's individual mandate to take up such coverage. These negative DD estimates for private coverage can be seen to represent "crowd-out" relative to the counterfactual represented by non-expansion states. However, these effects differ from common conceptions of crowd-out, i.e., people dropping private coverage when they become eligible for Medicaid. ${ }^{8}$

\footnotetext{
${ }^{6}$ Appendix Table A2 lists the complete set of coefficients (with the exception of the state dummies) from our estimation of equation (1) for the full sample.

${ }^{7}$ The ACS data do not include information on the source of employer-sponsored coverage (own coverage vs. spouse's; current vs. former employer). The fact that COBRA is available retroactively for several months after leaving a job complicates the interpretation of unemployed respondents' reports of either employer-sponsored or no coverage. Note that the potential mismeasurement of coverage does not affect our estimates of the effect of Medicaid expansion on transitions out of unemployment.

${ }^{8}$ Finkelstein et al (2012) find no evidence of crowd-out in the Oregon Health Insurance Experiment. The difference between that context and ours is that in the Oregon Experiment, the availability of private coverage was not changing for the control group. Frean, Gruber and Sommers (2017) find no evidence of crowd-out in their analysis of the first year of the ACA. The key difference between their analysis and ours is that they explicitly modeled the effect of the premium tax credits and the individual mandate. In our analysis, the effect of these policy elements are incorporated in the unexplained trend in nonexpansion states, which serves as the counterfactual for the changes observed in expansion states.
} 
The net effect of Medicaid expansion on insurance coverage of the unemployed, therefore, is an 8-percentage point decline in uninsurance. There are two ways to place the magnitude of this effect in context. The first is to compare it to the baseline rate of uninsurance among unemployed individuals in expansion states just prior to the implementation of the ACA provisions. This rate was 42.6 percent in 2013 , so an 8 -percentage point decline represents a reduction of nearly one-fifth of the baseline level. The second is to compare the estimated effect of Medicaid expansion to the overall decline in the percent uninsured that occurred for unemployed individuals in expansion states between 2013 and 2017, which also reflects the effects of other ACA provisions affecting private coverage and the improving economy. The overall decline over this period was 22.8 percentage points; so, the 8 -percentage point decline represents slightly over one-third of the total decline in uninsurance. Both of these comparisons confirm that the coverage gain among the unemployed due to Medicaid was not only statistically significant but also large in magnitude.

Effects for employed adults, in contrast, are much smaller in magnitude (Panel B of Table 3). Medicaid expansion was associated with a 3.5-percentage point increase in Medicaid coverage. However, this gain was almost fully offset by relative declines in private non-group (1.5 percentage points) and employer-sponsored insurance (1.1 percentage points). In the case of non-group insurance, coverage increased in both sets of states, but more so in non-expansion states. Again, this difference is due largely to the fact that individuals with incomes between 100 and 138 percent of the FPL gained Medicaid in expansion states and gained private non-group coverage through the marketplaces in non-expansion states. Employer-sponsored coverage had been declining slightly prior to 2014 and continued to do so in expansion states, while increasing very slightly in non-expansion states. The net effect of these offsetting changes is that there is no 
statistically significant difference in coverage gains between expansion and non-expansion states for the employed.

Looking at effects for different population subgroups among the unemployed (in the other columns of Table 3) shows that the effects of Medicaid expansion were felt widely across these groups, although results were somewhat larger for some groups than others; for example, non-parents benefited more than parents from Medicaid expansion, very likely because some very low-income parents already had access to Medicaid in some states.

Turning to the results of the more flexible event study specification (equation 2 above), the coefficients $\delta_{k}$ on the time-to/since-event dummies are presented graphically in Figure 2 for the four insurance coverage outcomes in the full sample of unemployed adults ages 26 through 64. ${ }^{9}$ These figures show two important things. First, there is no evidence of differential trends in outcomes across the two groups of states prior to Medicaid expansion. For Medicaid and uninsured, in particular, the event time dummies for $t$-6 (which is usually 2007) through $t-1$ (which is usually 2012) are not statistically different from zero (with the sole exception of $t-4$ coefficient in the Medicaid regression). Second, as expected, coverage effects were somewhat smaller in the first year of implementation (2014 in most states), increased in the second and third years of implementation, and then remained stable in the fourth year (2017 for most expansion states). Thus, the treatment dummy from model 1 that was reported in Table 3 -which averages the treatment effect across post-implementation years - somewhat understates the steady-state impact of Medicaid expansion that is observed in the third and fourth years of implementation. Similar results are obtained for each of the coverage outcomes for the sub-

\footnotetext{
${ }^{9}$ Appendix Table A2 lists the complete coefficient estimates (except for the state dummies) from the event history models for the full sample.
} 
groups listed in Table 3: insignificant time coefficients prior to expansion and significant effects in each year after expansion. ${ }^{10}$

\section{Analysis, Part 2: Access to Care}

\section{A. Data and Descriptive Analysis}

Next, we consider whether Medicaid expansion also improved access to care, using data from the Behavioral Risk Factor Surveillance Survey (BRFSS) from 2008 through 2017. The BRFSS is an annual cross-sectional survey conducted by states in conjunction with the Centers for Disease Control (Silva 2014). The full sample includes approximately 400,000 individuals in each year. After restriction to adults ages 26 through 64, the BRFSS has approximately 185,000 respondents in each year who are employed at the time of the survey and between 12,000 and 23,000 respondents who are unemployed at the time of the survey, depending on the year. ${ }^{11}$

We analyze four measures of access to care: (1) uninsured at the time of the survey; (2) needing to see a doctor at some point in the past 12 months but not doing so because of cost; (3) not having a usual source of medical care at the time of the survey; (4) not having had a routine checkup in the past 12 months. Access measures in the BRFSS generally benchmark well to other surveys (Skopec et al. 2014). However, the BRFSS measure of insurance coverage is far less detailed than the measures used in other surveys and does not distinguish between different sources of coverage (e.g. private versus public coverage), instead asking only whether

\footnotetext{
${ }^{10}$ Appendix Tables A3 through A6 list the estimated coefficients on the event history dummies for each of the four coverage outcomes for the complete set of subgroups listed in Table 3. The finding of no differential trends prior to expansion holds for all subgroups as well.

${ }^{11}$ The wording that the BRFSS uses to ask about employment status is "Are you currently employed for wages, self-employed, out-of-work for 1 year or more, out of work for less than 1 year, a homemaker, a student, retired, or unable to work?" We consider respondents who say that they are "out of work" to be unemployed.
} 
respondents have any coverage. For this reason, we view our ACS analyses of uninsurance as preferable to the analogous BRFSS analyses, although in practice the results are quite similar. Our empirical strategy for analyzing these outcomes is the same as our approach to analyze the ACS, so we begin with descriptive trends and then discuss difference-in-differences and event history models.

Figure 3 presents trends from BRFSS in each of our four access outcomes for unemployed and employed adults in expansion and non-expansion states. ${ }^{12}$ As with our analysis of coverage, these simple trends omit the seven states that expanded Medicaid after January 2014. Prior to 2014, these outcomes were trending similarly in expansion and non-expansion states. As in the ACS data, we see large declines in the fraction uninsured beginning in 2014 for unemployed individuals. We also observe declines in care delays (top right panel of Figure 3) and no usual source of care (lower left panel of Figure 3) that are particularly noticeable for the unemployed in Medicaid expansion states. The fraction of the unemployed with no checkup in the past 12 months had been declining since 2011, with no evident change in the trend beginning in 2014. For employed individuals, there are no evident changes in trends beginning in 2014 for any of these access measures.

\section{B. Regression Analysis}

These descriptive patterns suggest that large gains in coverage for the unemployed in Medicaid expansion states led to improvements in at least some measures of access to care, while the smaller coverage gains for the unemployed in non-expansion states and for the employed in all states did not yield measurable improvements in access. We test this hypothesis more

\footnotetext{
${ }^{12}$ Appendix Table A7 lists the numerical values.
} 
formally by estimating regression models based on equations (1) and (2) above with the access measures as outcomes.

Table 4 presents the estimated coefficients for the variable treatment from equation (1) for the four access outcomes. The top panel contains coefficients from models estimated on unemployed individuals. The results for the probability of being uninsured are generally similar to those from the ACS, suggesting that Medicaid expansion caused an 8 percentage point drop in the uninsured rate for the unemployed. Among employed adults, the BRFSS shows a small but statistically significant decline in the probability of being uninsured of just less than one percentage point (Panel B of Table 4). ${ }^{13}$

Two of the other access outcomes also show statistically significant effects of Medicaid expansion among the unemployed: a 4-percentage point drop in delayed/foregone care due to cost and a 2-percentage point drop in not having a usual source of care. The effect of Medicaid expansion on the probability of not having had a checkup in the past 12 months was negative (one percentage point) but statistically insignificant. These results are generally consistent across different population subgroups defined by education, parental status, etc., although the subgroup results are not always significant in some cases where the full-sample result is (e.g. for parents). Note that the BRFSS also includes self-reported health status (excellent, very good, good, fair, poor) so we are able to estimate separate analyses for the subgroup of individuals in fair or poor health, which is not possible in the ACS or basic monthly CPS. This group, like other relatively disadvantaged population groups, experienced somewhat larger gains in coverage and reductions in delayed care than other groups. Among employed workers, we find a small, significant reduction in the fraction reporting no usual source of care, but no significant changes in any

\footnotetext{
${ }^{13}$ Appendix Table A8 lists complete coefficient estimates (except for the state dummies) for the full sample, for the treatment and event study models.
} 
other measure of access to care. These null results are not surprising given that we do not find a large effect of Medicaid expansion on insurance coverage for this group.

The more flexible event study specification (Equation 2 above) for the access outcomes suggests that the simple DD model masks notable variation across outcomes and over time. Figure 4 plots the coefficients on event time dummies from each of these models estimated on the sample of unemployed adults. ${ }^{14}$ While the pre-event dummies are mostly not statistically significant - suggesting that the parallel trends assumption is satisfied - the post-event dummies are somewhat inconsistent, in contrast with the clear and consistent patterns that were observed for the ACS coverage results. For example, the "no usual source of care" post-event dummies are individually not significantly different from zero. The "delayed care" dummies follow a pattern that is most clearly consistent with the coverage results, with small and insignificant negative values in the first two years of implementation and larger, significant negative values in years 3 and 4. Standard errors on most of these estimates are fairly large, probably because of the relatively small sample size of unemployed people in each year in the BRFSS.

\section{Analysis, Part 3: Transitions out of Unemployment}

\section{A. Labor Market Conditions in Expansion/Non-expansion States}

After establishing the effects of Medicaid expansion on insurance coverage and access to care for the unemployed, we now turn to an examination of its effects on job search. Proper design and interpretation of this analysis requires incorporation of state labor market conditions and relevant elements of the state policy environment, other than Medicaid expansion status, that may differ between expansion and non-expansion states.

\footnotetext{
${ }^{14}$ Appendix Tables A9-A12 provide the numerical estimates of the event history coefficients for the subgroups listed in Table 4. The subgroup results are largely similar to the full sample results discussed here.
} 
Figure 5 displays some key differences between expansion and non-expansion states, using monthly data that extends from the beginning of 2007, just before the start of the Great Recession, into early $2018 .{ }^{15}$ Panel A shows that expansion states generally had higher unemployment rates, reflecting weaker labor market conditions, throughout the sample frame. Changes in the unemployment rate generally track each other across the two groups of states. The exception is during the period just before and just after January 2014, exactly when the Medicaid expansions came into effect. The unemployment rate gap grew during the few years leading up to January 2014 and then shrank noticeably after January 2014.

Panel B of Figure 5 illustrates one potential reason why the unemployment rate gap between expansion and non-expansion states shrank after January 2014. This panel plots the average number of total UI weeks available in the two groups of states. Changes over time in UI availability reflect the legislative rollout, expansion, and eventual withdrawal of the extended benefits during the Great Recession and recovery (see Valletta 2014 and Rothstein and Valletta 2017 for details). The expansion states had higher maximum UI weeks available during most of the sample frame, reflecting their weaker labor market conditions. As the figure shows, this also means that the expansion states experienced a larger withdrawal of available UI benefits when the EUC program was terminated at the end of 2013. In addition, various non-expansion states reduced their normal UI benefits below 26 weeks during 2011-forward, causing available UI weeks in non-expansion states to remain below that of expansion states from 2014 forward. Accurate assessment of potential moral hazard effects of the Medicaid expansions -i.e., reduced job finding or labor force attachment — requires drilling down beneath broad labor

\footnotetext{
${ }^{15}$ The aggregate statistics for the separate groups of expansion and non-expansion states are weighted, as described in the figure note. As in the earlier descriptive figures, we limit the set of Medicaid expansion states to those that expanded by January 2014; subsequent regression models include all states.
} 
market indicators such as the unemployment rate and unemployment duration. In particular, recent research on the impact of the UI extensions that occurred during the Great Recession distinguished between their impact on job-finding rates and labor force attachment or withdrawal (Rothstein 2011; Valletta 2014; Farber, Rothstein, and Valletta 2015; Farber and Valletta 2015). These papers generally find a limited impact of UI availability on job finding rates during this timeframe. Instead, extended UI tends to increase the duration of job search and hence unemployment durations via reduced labor force exit rates. This suggests limited moral hazard effects on labor supply. However, an examination of unemployment rates or durations alone that did not distinguish between these two types of transitions out of unemployment would suggest adverse effects of UI on search behavior and labor supply.

The Medicaid expansions may affect unemployment duration through two different mechanisms. First, some unemployed individuals may withdraw from the labor force altogether as a result of the availability of free health insurance that is not linked to employment. While this would reduce both the prevalence and duration of unemployment, this labor force withdrawal would represent a moral hazard effect - negative and unintended - of the policy. Second, some unemployed individuals who receive Medicaid via the expansions may delay their return to employment because, for example, Medicaid reduces the urgency of obtaining employersponsored insurance. These individuals may find that Medicaid enables them to engage in lengthier job search. This behavior will tend to increase measured unemployment rates and durations, and would constitute evidence of moral hazard (although we note that the lengthier search may ultimately result in higher-quality re-employment matches). ${ }^{16}$ Given these possible

\footnotetext{
${ }^{16}$ As discussed in Section IIA, the reduction in labor force exits induced by the recent UI extensions is consistent with other research suggesting that UI has limited moral hazard effects (Chetty 2008; Card, Chetty, and Weber 2007).
} 
alternative impacts of the Medicaid expansions on unemployed individuals, we focus our analyses on transitions out of unemployment, distinguishing between exits via job finding and labor force withdrawal. The regression framework and results are described in the next two subsections.

\section{B. Data and Empirical Strategy}

Given the close relationship between Medicaid expansions, available UI benefits, state labor market conditions, and labor market outcomes, detailed microdata are required to assess the independent effects of the Medicaid expansions. Such data allow us to isolate the effects of the Medicaid expansions and obtain estimated impacts on job search that are uncontaminated by the other changes in state labor markets and their policy environments.

We use matched monthly data on individual labor force participants from the CPS. As with our analysis of insurance coverage and access to care, we restrict the sample to individuals age 26-64 in order to minimize the influence of the ACA dependent coverage provision. The sample period is January 2007 through December 2017, which enables reliance on a prerecession year (2007) as a reference point. We include individuals unemployed as a result of job loss/layoff, voluntary quits, and labor force re-entry. We exclude new entrants to the labor force; their job search behavior is likely to differ from experienced labor force participants, and we do not observe selected regression controls for them (industry of prior job). In addition to the primary sample, we also discuss results from a sub-sample limited to job losers below. ${ }^{17}$

Due to the rotating sampling scheme used for the CPS, surveyed households and individuals are in the sample for two separate periods of 4 consecutive months (with an

\footnotetext{
${ }^{17}$ See Valletta (2014) for more details on construction of a similar sample for an earlier timeframe (in particular, Table 2 and the associated discussion in that paper).
} 
intervening 8-month period spent out of the sample). This enables consecutive month-to-month matching for about $70 \%$ of the sample. ${ }^{18}$ The monthly match is based on household identifiers and validated by ensuring that the reported data on age, education, race, and gender do not conflict across matched observations. We identify labor market transitions by comparing an individual's labor force status in month $t$ to that in month $t+1$.

A well-known concern regarding matched CPS data is the likelihood of spurious transitions in labor force status arising from inconsistent or error-ridden survey responses rather than meaningful changes (Abowd and Zellner 1985; Poterba and Summers 1986, 1995). Such spurious transitions could impart a downward bias to the estimated effect of Medicaid on unemployment exits and might also reduce the precision of the estimates. We therefore follow past research by adjusting the data to minimize the incidence of spurious transitions (Rothstein 2011, Valletta 2014, Farber and Valletta 2015, Farber, Rothstein, and Valletta 2015). In particular, for individuals identified as leaving unemployment one month, either through job finding or labor force exit, and then returning to unemployment the next month, their records are recoded to show no transition (and the newly created observations are retained). This correction requires restriction of the final analysis sample to individuals who are observed to be in their first or second month of a consecutive four-month span in the sample. We refer to these as "twomonth forward matches." All results reported below are based on these restricted matches and corresponding measured transitions. The results are similar but less precisely estimated when this

\footnotetext{
${ }^{18}$ Most of the non-matched observations are from the "outgoing rotation groups" that are exiting the sample for eight months or permanently (one quarter of each monthly sample). In addition, a modest fraction of observations is lost because respondent households that move to different geographic locations are not followed.
} 
restriction is not imposed (i.e., when the wider set of single-month matches and transitions are used). ${ }^{19}$

Our analyses of transitions out of unemployment parallels the earlier analyses of insurance coverage and access to care, starting with descriptive analyses and proceeding to difference-in-differences and event history regressions. Figure 6 presents simple trends in the probability of different transitions out of unemployment, for Medicaid expansion and nonexpansion states. ${ }^{20}$ Although the data are monthly, the figure depicts calendar year averages. As in the earlier figure, we dropped the seven states that expanded Medicaid after January 2014; these will be included in our regression analyses below. The figure shows that rates of both types of transitions (exit to employment and exit to not in the labor force, or NILF) exhibit generally similar trends both before and after 2014 for expansion and non-expansion states: year by year, the confidence intervals for mean transition rates for the two groups of states always overlap.

\section{Regression Specification and Results}

We estimate regressions of the following form using the monthly CPS matched data corrected for spurious transitions:

$$
E_{i s t}=\beta \cdot \text { treatment }_{s(t+1)}+\alpha_{s}+\gamma_{t}+X_{i s t}^{\prime} \phi+W_{s(t+1)}^{\prime} \rho+M_{t}+\psi \text { duration }_{\text {ist }}+v_{\text {ist }}
$$

\footnotetext{
${ }^{19}$ This correction requires restriction of the final analysis sample to individuals who are observed to be in their first or second month of a consecutive four-month span in the CPS sample, thereby reducing the matched sample count by approximately one-third. Figure 2 in Valletta (2014) shows that the correction reduces measured exit rates by about 5 to 10 percentage points across the distribution of unemployment durations.

${ }^{20}$ The corresponding numerical estimates are listed in Appendix Table A13.
} 
The dependent variable $E$ ("exit") is an indicator for whether an individual $i$ living in state $s$ who is unemployed in the survey reference week in month $t$ exits unemployment by month $t+1$ (i.e., reports no longer being unemployed in the reference week in the subsequent survey month). Exits from unemployment can occur either through job finding (exit to employment) or labor force withdrawal (exit to "not in labor force," or NILF); we estimate separate equations for each exit route. Estimation is via a linear probability model. All estimates are weighted by the CPS survey weights, and robust standard errors are provided (clustered by state, hence the disturbance term $v$ in equation 3 has underlying components).

Explanatory variables are defined as in equation 1, with three additional vectors of controls: a set of indicator variables for broad industry of prior employment (14 categories); indicators for the duration to date of the individual's unemployment spell (10 categories, with the final category indicating duration of longer than one year); and a vector of calendar month dummies $M_{t}$. The observation count for these regressions using the full available sample is 166,838 (see Table 5 for sub-group sample sizes). Treatment status and state labor market conditions are measured in month $t+1$, to directly account for their potential effects on transitions measured in that same month.

As in the earlier estimates, in addition to state labor market conditions-cubics in the unemployment rate and rate of payroll employment growth — the vector of state labor market controls includes maximum available UI weeks. This is crucial for our estimation strategy. The abrupt elimination of extended UI benefits at the end of 2013 corresponds closely to the main Medicaid expansions in January 2014 and hence is a potential confounding element in our estimation: the withdrawal of extended UI benefits may offset the expansion of Medicaid, with a greater offset occurring in the Medicaid expansion states due to their larger loss of maximum UI 
availability (discussed in the preceding sub-section). Our measure of maximum available UI weeks, which differs across states and months, accounts for this abrupt change in UI availability. It also accounts for monthly changes in each state's maximum UI availability that occurred at any time during our sample frame, due to the tiered structure of the federal extended UI legislation and also changes in state-specific regular UI weeks. Although not reported in the tables, the estimated coefficients on the UI weeks variable in our regressions are consistent with the findings from past papers that focus on the effects of the UI extensions (e.g., Rothstein 2011, Valletta 2014, Farber and Valletta 2015, Farber, Rothstein, and Valletta 2015). ${ }^{21}$

Table 5 presents estimates of the treatment coefficient $\beta$ from equation 3 for the full sample of unemployed adults as well as subgroups defined as above by gender, education, parental status, and duration of unemployment. ${ }^{22}$ These estimates provide no evidence in favor of meaningful moral hazard effects of the Medicaid expansions. Although the estimates of the difference-in-difference coefficient $\beta$ in the employment exits equation are negative for the full sample and some sub-samples, they are very small and statistically insignificant in all cases.

In the full sample and 4 of the 6 subsamples, the estimated treatment $\beta$ 's for transitions out of the labor force are not statistically significant. In the two cases where the coefficient estimates are significantly different from zero—-for parents and for individuals who were

\footnotetext{
${ }^{21}$ The estimated coefficients on UI weeks in our regressions indicate that longer maximum UI durations are associated with reduced exits out of the labor force but no meaningful effect on job finding. The earlier work cited relied on our UI duration variable and also availability measured at the individual level (via comparisons between reported unemployment duration and available UI weeks, with samples restricted to job losers who are likely eligible for UI). We do not use these individual comparisons in the present work, to allow for more general effects of the UI extensions on state labor market conditions and also because many individuals in our analysis samples are not eligible to receive UI.

${ }^{22}$ Estimation by duration of unemployment corresponds approximately to the estimation by "when last worked" for the coverage and access outcomes in earlier sections. Because an individual may be unemployed due to labor force re-entry, duration of unemployment will not necessarily correspond to the time elapsed since leaving a prior job. The specific timeframe since prior employment is not available in the monthly CPS data for all unemployed individuals.
} 
unemployed for less than a year-the estimates are negative, indicating that the expansion of Medicaid made unemployed workers less likely to drop out of the labor force. This is the opposite of what we would find if the effect of the expansion was to reduce labor force attachment, i.e., if there was a moral hazard effect. This pattern of results also does not line up neatly with the evidence of heterogeneous treatment effects for insurance coverage. The ACA Medicaid expansions led to smaller gains in insurance coverage for parents than for childless adults; the expansions had similar effects on individuals who were unemployed for more or less than one year. Thus, while the explanation for these two statistically significant estimates is not clear, they do not fit with the hypothesis that Medicaid expansion leads to reduced labor force attachment.

Figure 7 plots the event time dummies from models estimated using the full sample but substituting these complete time effects for the single treatment dummy, as in our analyses of coverage and access presented earlier. These event time dummies exhibit no clear pattern and generally are not significantly different from zero. ${ }^{23}$ These results confirm both that there are no significant differential trends in employment transitions prior to the implementation of Medicaid and also that there is no clear pattern of changes in exit rates after the implementation of Medicaid expansion. ${ }^{24}$

\section{Robustness checks}

${ }^{23}$ The pattern of time effects generally supports the conventional parallel trends assumption that is necessary to interpret the post-expansion changes as treatment effects.

${ }^{24}$ Appendix Table A14 lists the complete coefficient estimates (except on the state, calendar month, and industry categories) for the treatment and event study results for the full sample. Appendix Table A15 lists the event history coefficients for the sub-samples listed in Table 5. 
In addition to the comparisons across sub-samples, we subjected our results to several robustness checks. First, we dropped the six "early expansion" states that partially implemented the Affordable Care Act's Medicaid expansion prior to January 2014 (California, Connecticut, Washington DC, Minnesota, New Jersey, and Washington State). The inclusion of these states potentially biases our effects since the policy might have begun to have an effect prior to what we are measuring as the implementation date of January 2014. Therefore, we drop the residents of these six states, reducing our sample size by approximately one quarter, and re-estimate the main results of our DD analysis of the unemployed: insurance coverage from ACS, access to care from BRFSS, and transitions out of unemployment from the CPS. Table 6 juxtaposes key results from Tables 3,4 , and 5 that were estimated using the full sample of states (column 1) with results estimated dropping the early expansion states (column 2). It is evident from this comparison that dropping the early expansion states changes the results very little.

A more serious threat to the validity our study design is the fact that the majority of state Medicaid expansions occurred on January 1, 2014, immediately after the abrupt withdrawal of extended benefit availability at the end of 2013. Although our analyses control for the UI benefits available at the state-year level (for our analyses of coverage and access) or the statemonth level (for our analyses of employment transitions), this may not adequately control for the effects of this policy change. If that is the case, our main results may underestimate any negative effect of Medicaid on job search behavior. Therefore, we re-estimate our main analyses using only the seven states that expanded Medicaid after January 2014: Michigan, New Hampshire, Pennsylvania, Indiana, Alaska, Montana, and Louisiana (compared with all of the non-expansion states). For these states, the timing of Medicaid expansion did not coincide with the elimination of extended UI benefits. This reduces our sample of unemployed individuals by 60 percent (see 
bottom row of Table 1). The "late expansion" states contained 7 percent of our original sample, so the restricted sample, consisting of late expansion states and non-expansion states only, is approximately 20 percent late expansion and 80 percent non-expansion.

Column 3 of Table 6 contains results estimated using only the late expansion and nonexpansion states. The effects on insurance coverage, reported in the upper panel of Table 6 , are quite similar in both samples. The estimated effect of the expansion on the probability of being uninsured is slightly lower in the late expander sample (-0.068 vs. -0.080$)$, though the estimate for the late expanders is more heavily weighted toward year 1 effects, which as shown in Figure 2 tend to be smaller than effects in later years. Taking this into account, the results suggest that late expansions were as effective as the January 2014 expansions at increasing coverage.

The employment transition results are shown in the lower panel of Table 6. In the late expansion sample, Medicaid expansion is associated with an increase in transitions from unemployment to employment. This result is inconsistent with the hypothesis that the availability of Medicaid coverage when unemployed reduces job search. However, like the results for the full sample, where the point estimate is negative, the estimated coefficient for the late expansion sample is not significantly different from zero. Similarly, we see no statistically significant relationship between Medicaid expansion and labor force exits in the late expansion states.

We conducted two more sets of analyses focusing on labor market transitions in order to make sure we are not overlooking moral hazard effects. First, we restricted the sample to job losers, who are likely to be most responsive to job-search incentives via UI eligibility and their demonstrated labor force attachment (reflected in prior employment). As expected, the estimated effects of UI availability in this sub-sample of likely UI eligibles were larger and more precisely estimated than in the full sample. However, like the full sample results, the difference-in- 
difference tests for the Medicaid expansions in this sub-sample yielded no statistically reliable evidence of moral hazard effects as a result of Medicaid on job finding or labor force exit. We also examined additional transitions along the labor force participation margin, specifically transitions in both directions between employment and NILF, and also transitions from NILF back to active job search (unemployment). These analyses address the possibility that the moral hazard effects of Medicaid availability are not restricted to currently unemployed individuals. Difference-in-difference tests that parallel those described above once again revealed no discernible impact of the Medicaid expansions on transition rates between labor force states (results available on request).

Finally, we examined a potential threat to the validity of the labor market transition analysis. The event history results displayed in Figure 7 suggest similar pre-treatment trends in expansion and non-expansion states. However, Medicaid expansion may have induced changes in the composition of the unemployed that differ between expansion and non-expansion statesfor example, a shift in composition toward more skilled individuals, which could bias the estimated treatment effects. This possibility is addressed in Appendix Figures A1 and A2, which display the pattern over time in the fitted probabilities of unemployment exits based on the observable individual controls used in our regressions. The predicted exits to employment and NILF are consistently lower in expansion states. However, the plots show very small differences between expansion and non-expansion states and no meaningful change in the relative predicted exit rates after expansion (using 2014 as the post-expansion baseline for all non-expansion states). ${ }^{25}$ While we cannot reject the possibility of systematic changes in unobservable

\footnotetext{
${ }^{25}$ Figure A1 displays the separate predictions for expansion and non-expansion states, and Figure A2 displays the difference between them. There is an increase in the relative predicted probability of labor force exits in expansion states around 2014, which is most evident in Figure A2. This may cause understatement of the finding that Medicaid expansion reduced labor force exits for selected groups in
} 
characteristics of workers between expansion and non-expansion states, the results based on observables suggest that compositional changes are not a concern.

\section{Discussion}

What explains our finding that expanded Medicaid eligibility had minimal effects on transitions out of unemployment, with the only detectable effect (for selected sub-groups) taking the form of reduced labor force withdrawal rather than reduced job finding? These results cannot be attributed to a weak "first stage," given that we find that the expansion substantially increased the health insurance coverage of unemployed workers. A more likely explanation is that the value of this in-kind benefit to the average unemployed worker was not large. In 2014, average annual Medicaid spending for non-disabled adult beneficiaries was just over $\$ 3,000 .{ }^{26}$ However, much of this spending is on care that beneficiaries would have received for free if they were uninsured. Finkelstein, Hendren and Luttmer (2019) conclude that roughly 60 percent of Medicaid spending can be thought of as transfers to hospitals and other parties that subsidize the care receive by the uninsured. ${ }^{27}$ Thus, the net transfer to beneficiaries is closer to $\$ 1,200$ to $\$ 1,400$ per year. To put this in perspective, the typical monthly UI benefits during our sample period were about $\$ 1,300$. Moreover, research on UI benefit extensions over our sample period

\footnotetext{
Table 5, but the magnitude of the composition effect is quite small. These results are similar when the individual controls are expanded to include complete interactions between age, education, gender, and marital status ( 80 categories) along with the other individual covariates.

${ }^{26}$ Source: Kaiser Family Foundation State Health Facts, https://www.kff.org/medicaid/stateindicator/medicaid-spending-per-enrollee/

${ }^{27}$ Hospitals are effectively "insurers of last resort" through the provision of uncompensated care (Garthwaite et al 2018). Bankruptcy also represents a form of implicit insurance (Mahoney 2015). Recent studies have found that the ACA Medicaid expansion led to a decrease in hospital uncompensated care (Blavin 2016; Rhodes et al 2019) and an improvement in household financial well-being (Hu et al 2017). Other research finds little impact of the Medicaid expansion on household expenditures (Levy, Buchmueller and Nikpay 2018), which also suggests that the uninsured spend very little on medical care.
} 
finds only small effects of the extensions on transitions out of unemployment, with most of the effect arising through reduced labor force exits rather than reduced job finding (e.g., Farber and Valletta 2015). Our results showing no detectable effect on job finding but reduced labor force withdrawals in response to Medicaid extensions for selected sub-groups (Table 5) are consistent with these findings for the effects of UI extensions. ${ }^{28}$

It is also important to keep in mind that our analysis identifies the effect of the availability of Medicaid in the context of the other ACA reforms, which provide affordable insurance options for individuals and families with incomes above the Medicaid eligibility threshold. An unemployed worker who finds a job that raises their income above 138 percent of poverty will be eligible for tax credits that defray much of the cost of private insurance. This will further reduce any possible work disincentives.

Even if it is not surprising, the null effect of Medicaid eligibility on the job search behavior of unemployed workers is highly relevant to ongoing policy debates. Beginning in 2017, several states have sought waivers to introduce work requirements to their Medicaid programs (Musumeci et al 2018). In pushing for their greater use in all non-cash safety net programs, the Trump administration has argued that work requirements will increase employment, thereby improving "self-sufficiency" (Council of Economic Advisers 2018). Our results, along with those of other recent studies finding no employment effects of the ACA Medicaid expansion, are at odds with this assertion. Our results are more consistent with a recent study of Arkansas, which in June 2018 became the first state to implement Medicaid work requirements. Sommers et al (2019) found that the introduction of work requirements led to

\footnotetext{
${ }^{28}$ Other recent quasi-experimental evidence finds substantial moral hazard effects of the UI extensions (Card et al. 2015; Johnston and Mas 2018). However, this research is based on data for one state, Missouri, and the findings may not generalize to the wider national sample that we examine to assess the impacts of Medicaid expansions.
} 
roughly a 6-percentage point reduction in insurance coverage in Arkansas relative to changes in three control states, but no significant change in employment.

\section{Conclusions}

Because employer-sponsored insurance is the predominant source of health coverage in the United States, many workers who lose their jobs not only suffer a loss of income but also lose health insurance. By creating new affordable insurance options that are not tied to employment, the Affordable Care Act was intended to strengthen the safety net for unemployed workers and other Americans with limited access to employer-sponsored insurance. The effect of the ACA on increasing insurance coverage was limited by the decision of some states to not implement the expansion of the Medicaid program as intended by the law.

Our analysis of health insurance coverage trends over a ten-year period finds that the ACA Medicaid expansion significantly expanded the safety net for unemployed workers. Difference-in-differences estimates indicate that after the law went into effect, the percent uninsured among the unemployed fell by an additional 8 percentage points in states that implemented the Medicaid expansion compared to states that did not. Increases in insurance coverage were particularly large for demographic groups that prior to 2014 had limited access to public insurance coverage. We also find greater improvements in access to care for the unemployed in expansion states compared to non-expansion states.

A full evaluation of the ACA requires accounting for possible market distortions arising from incentives created by the program. Before the main coverage provisions of the law went into effect, much attention was given to potential labor market distortions. In the case of unemployed workers, access to Medicaid might have reduced the intensity of job search, thereby 
reducing exit from unemployment to employment; at the same time, access to Medicaid may have led unemployed individuals to exit the labor force altogether. Our analysis distinguishes between exits via job finding and exits out of the labor force, which may move in opposite directions in response to the Medicaid expansions and hence have offsetting effects on measured unemployment. Our difference-in-difference tests show no meaningful effects of the Medicaid expansions on job finding but a reduction in labor force exits for some groups (parents and the short-term unemployed). This suggests no moral hazard effects on labor market behavior arising from the expansions, and in fact modest positive effects on labor force attachment.

Overall, our results suggest that the expansions of Medicaid availability to unemployed individuals under the ACA achieved their intended effect of expanding coverage without causing adverse unintended consequences via moral hazard effects on job search and labor force attachment. Our findings do not preclude more general negative labor supply effects of the ACA, as assumed in CBO analyses (Harris and Mok 2015). However, our findings suggest that such labor supply effects as a result of the ACA Medicaid expansions have been minimal. 


\section{References}

Abraham, Katharine G., and Melissa S. Kearney. 2018. "Explaining the Decline in the U.S. Employment-to-Population Ratio: A Review of the Evidence." NBER Working Paper No. 24333, February. http://www.nber.org/papers/w24333

Akosa Antwi, Y., Moriya, A.S., and Simon, K., 2013. "Effects of Federal Policy to Insure Young Adults: Evidence from the 2010 Affordable Care Act's Dependent-Coverage Mandate," American Economic Journal: Economic Policy, 5(4): 1-28.

Antonisse, Larisa, Rachel Garfield, Robin Rudowitz, and Samantha Artiga. 2017. The Effects of Medicaid Expansion under the ACA: Updated Findings from a Literature Review. Kaiser Family Foundation Issue Brief.

Baicker, K., Finkelstein, A., Song, J. and Taubman, S., 2014. The impact of Medicaid on labor market activity and program participation: evidence from the Oregon Health Insurance Experiment. American Economic Review, 104(5), pp.322-28.

Bailey, J. and Chorniy, A., 2016. "Employer-Provided Health Insurance and Job Mobility: Did the Affordable Care Act Reduce Job Lock?" Contemporary Economic Policy, 34(1): 17383.

Baily, Martin N. 1978. "Some Aspects of Optimal Unemployment Insurance." Journal of Public Economics. 10 (December): 379-402.

Barbaresco, S., Courtemanche, C., and Qi, Y., 2015. "Impacts of the Affordable Care Act Dependent Coverage Provision on Health-Related Outcomes of Young Adults," Journal of Health Economics, 40(1)): 54-68.

Barnett, J.C. and Berchick, E.R., 2017. "Health Insurance Coverage in the United States: 2016," Current Population Reports, P60-260(September).

Blumberg, Linda J. Bowen Garrett, and John Holahan. 2016. "Estimating the Counterfactual: How Many Uninsured Adults Would There Be Today Without the ACA?" Inquiry 53(3): $1-13$.

Bradley, C.J. and L.M Sabik. forthcoming. "Medicaid Expansions and Labor Supply Among Low-Income Childless Adults: Evidence from 2000 to 2013.” International Journal of Health Economics and Management 19 (3-4): 235-272.

Browning, M. and Crossley, T.F., 2009. Shocks, stocks, and socks: Smoothing consumption over a temporary income loss. Journal of the European Economic Association, 7(6), pp.11691192.

Buchmueller, T.C., Ham, J and Shore-Sheppard, L. 2016. "The Medicaid Program," in The Economics of Means-Tested Transfer Programs edited by Robert Moffit, Chicago: University of Chicago Press. 
Buchmueller, T.C., Levinson, Z.M., Levy, H.G. and Wolfe, B.L., 2016. Effect of the Affordable Care Act on racial and ethnic disparities in health insurance coverage. American Journal of Public Health, 106(8), pp.1416-1421.

Buchmueller, T.C. and Valletta, R.G., 2017. Work, Health, and Insurance: A Shifting Landscape for Employers and Workers Alike. Health Affairs, 36(2), pp.214-221.

Card, David, Raj Chetty, and Andrea Weber. 2007. "The Spike at Benefit Exhaustion: Leaving the Unemployment System or Starting a New Job?" American Economic Review 97(2): $113-118$.

Card, David, and Phillip B. Levine. 2000. "Extended benefits and the duration of UI spells: evidence from the New Jersey extended benefit program." Journal of Public Economics 78: 107-138.

Card, David, Andrew Johnston, Pauline Leung, Alexandre Mas, and Zhuan Pei. 2015. “The Effect of Unemployment Benefits on the Duration of Unemployment Insurance Receipt: New Evidence from a Regression Kink Design in Missouri, 2003-2013." American Economic Review 105 (5): 126-30.

Chan, S. and Stevens, A.H., 1999. Employment and retirement following a late-career job loss. The American Economic Review, 89(2), pp.211-216.

Chetty, R. (2006). A General Formula for the Optimal Level of Social Insurance. Journal of Public Economics, 90, 1879-1901.

Chetty, R., 2008. Moral hazard versus liquidity and optimal unemployment insurance. Journal of Political Economy, 116(2), pp.173-234.

Coleman, G. and Dave, D., 2018. "It's About Time: Effects of the Affordable Care Act Dependent Coverage Mandate on Time Use," Contemporary Economic Policy 36(1):4458.

Courtemanche, C., Marton, J., Ukert, B., Yelowitz, A., and Zapata, D., 2017. "Early Impacts of the Affordable Care Act on Health Insurance Coverage in Expansion and Non-Expansion States," Journal of Policy Analysis and Management, 36(1): 178-210.

Dague, L., DeLeire, T. and Leininger, L., 2017. The effect of public insurance coverage for childless adults on labor supply. American Economic Journal: Economic Policy, 9(2), pp.124-54.

Deleire, T., 2018, "The Effect of Disenrollment from Medicaid on Employment, Insurance Coverage, Health and Health Care Utilization," NBER Working Paper No. 24899. 
Duggan, M., Goda, G.S. and Jackson, E., 2017. "The Effects of the Affordable Care Act on Health Insurance Coverage and Labor Market Outcomes," NBER Working Paper No. 23607 (July).

Fang, C., 2017. "The Effect of Affordable Care Act Medicaid Expansion on Post-Displacement Labor Supply among the Near-Elderly.” Ann Arbor, MI: University of Michigan Retirement Research Center (MRRC) Working Paper, WP 2017-370. http://mrrc.isr.umich.edu/wp370/.

Farber, H.S., 2017. Employment, hours, and earnings consequences of job loss: US evidence from the displaced workers survey. Journal of Labor Economics, 35(S1), pp. S235-S272.

Farber, H.S. and Valletta, R.G., 2015. Do extended unemployment benefits lengthen unemployment spells? Evidence from recent cycles in the US labor market. Journal of Human Resources, 50(4), pp.873-909.

Farber, H.S., Rothstein, J. and Valletta, R.G., 2015. "The Effect of Extended Unemployment Insurance Benefits: Evidence from the 2012-2013 Phase-Out," American Economic Review, 105(5): 171-176.

Finkelstein, Amy, Nathaniel Hendren, and Erzo F.P. Luttmer. Forthcoming. The Value of Medicaid: Interpreting Results from the Oregon Health Insurance Experiment. Journal of Political Economy.

Frisvold, D.E., and Jung, Y., 2018. "The Impact of Expanding Medicaid on Health Insurance Coverage and Labor Market Outcomes," International Journal of Health Economics and Management, 18(2): 99-121.

Garfield, R., Rudowitz, R., Musumeci, M.B., and Damico, A., 2018. "Implications of Work Requirements in Medicaid: What Does the Data Say?" Kaiser Family Foundation Issue Brief, available at http://files.kff.org/attachment/Issue-Brief-Implications-of-WorkRequirements-in-Medicaid-What-Does-the-Data-Say

Garthwaite, C., Gross, T. and Notowididgo, M., 2014. "Public Health Insurance, Labor Supply and Employment Lock," Quarterly Journal of Economics, 129(2): 653-696.

Gooptu, A., Moriya, A.S., Simon, K.I. and Sommers, B.D., 2016. Medicaid expansion did not result in significant employment changes or job reductions in 2014. Health Affairs, 35(1), pp.111-118.

Gruber, J., 1997. The Consumption Smoothing Benefits of Unemployment Insurance. The American Economic Review, 87(1), pp.192-205.

Gruber, J. and Madrian, B.C., 1997. Employment separation and health insurance coverage. Journal of Public Economics, 66(3), pp.349-382. 
Gruber, J. and Madrian, B.C., 2002. "Health Insurance, Labor Supply and Job Mobility: A Critical Review of the Literature," NBER Working Paper No. 8817 (February).

Hacker, J.S., 2006. The Great Risk Shift: The New Economic Insecurity and the Decline of the American Dream. Oxford University Press.

Ham, J.C. and Ueda, K., The Perils of Relying Solely on the March CPS: The Case of Estimating the Effect on Employment of the TennCare Public Insurance Contraction.

Harris, E., Mok, S., 2015. "How CBO Estimates the Effects of the Affordable Care Act on the Labor Market," Congressional Budget Office Working Paper Series No. 2015-09 (December).

Heim, B., Lurie, I., and Simon, K., 2015. "The Impact of the Affordable Care Act Young Adult Provision on Labor Market Outcomes: Evidence from Tax Data," in Tax Policy and the Economy, 29(1): 133-157.

Johnston Andrew C., and Alexandre Mas 2018. "Potential Unemployment Insurance Duration and Labor Supply: The Individual and Market-Level Response to a Benefit Cut." Journal of Political Economy 126(6): 2480-2522.

Jolly, N.A. and Phelan, B.J., 2017. The Long-Run Effects of Job Displacement on Sources of Health Insurance Coverage. Journal of Labor Research, pp.1-19.

Jurajda, S. and F.J. Tannery. 2003. "Unemployment Durations and Extended Unemployment Benefits in Local Labor Markets." Industrial and Labor Relations Review 56(2): 324348.

Kaestner, R., Garrett, B., Chen, J., Gangopadhyaya, A. and Fleming, C., 2017. Effects of ACA Medicaid expansions on health insurance coverage and labor supply. Journal of Policy Analysis and Management, 36(3), pp.608-642.

Kalil, A. and Wightman, P., 2011. Parental Job Loss and Children's Educational Attainment in Black and White Middle-Class Families. Social Science Quarterly, 92(1), pp.57-78.

Katz, L. and Krueger, A.B. 2016. "The Rise and Nature of Alternative Work Arrangements in the United States, 1995-2015," NBER Working Paper No. 22667.

Katz, L., and Meyer, B. 1990. "The Impact of the Potential Duration of Unemployment Benefits on the Duration of Unemployment." Journal of Public Economics 41 (Feb.): 45-72.

Kreuger, A. and B. Meyer., 2002. "Labor Supply Effects of Social Insurance,” Handbook of Public Economics,

Kucko, K., Rinz, K. and Solow, B. 2018. "Labor Market Effects of the Affordable Care Act: Evidence from a Tax Notch." Unpublished working paper. 
Landais, Camille. 2015. "Assessing the Welfare Effects of Unemployment Insurance Using the Regression Kink Design.” American Economic Journal: Economic Policy 7 (4): 243-78.

Leung, P. and Mas, A., 2018. "Employment effects of the ACA Medicaid expansions." Industrial Relations, 57(2): 206-234.

Levy, H., Buchmueller, T.C. and Nikpay, S., 2016. Health reform and retirement. Journals of Gerontology Series B: Psychological Sciences and Social Sciences, p.gbw 115.

Levy, H., Buchmueller, T.C. and Nikpay, S., 2018. The Impact of Medicaid Expansion on Household Consumption. Eastern Economic Journal pp. 1-24.

McMorrow, S., Long, S.K., Kenney, G.M. and Anderson, N., 2015, "Uninsured Disparities Have Narrowed for Black and Hispanic Adults under the Affordable Care Act," Health Affairs, 34(10):1774-1778.

Meyer, B.D. 1990. "Unemployment Insurance and Unemployment Spells." Econometrica 58: 757-782.

Moffitt, R. 1985. "Unemployment Insurance and the Distribution of Unemployment Spells." Journal of Econometrics 28: 85-101.

Morduch, J. and Schneider, R., 2017. The Financial Diaries: How American Families Cope in a World of Uncertainty. Princeton University Press.

Musumeci, M., Garfield, R. and Rudowitz, R. 2018. "Medicaid and Work Requirements: new Guidance, State Waiver Details and Key Issues," Kaiser Family Foundation Issue Brief (January).

Pohl, R.V. 2018. "Medicaid and the Labor Supply of Single Mothers: Implications for Health Care Reform." International Economic Review, 59(3): 1283-1313.

Rothstein, J. 2011. "Unemployment Insurance and Job Search in the Great Recession." Brookings Papers on Economic Activity (Fall):143-96.

Rothstein, J. and Valletta, R.G., 2017. Scraping by: Income and program participation after the loss of extended unemployment benefits. Journal of Policy Analysis and Management, 36(4), pp.880-908.

Schaller J, Stevens AH (2015) Short-run effects of job loss on health conditions, health insurance, and health Care utilization. Journal of Health Economics, 43, pp.190-203.

Schwartz, J. 2013. "Do Temporary Extensions to Unemployment Insurance Benefits Matter? The Effects of the US Standby Extended Benefit Program." Applied Economics 45 (March): 1167-83. 
Silva, N.M., 2014. The behavioral risk factor surveillance system. The International Journal of Aging and Human Development, 79(4), pp.336-338.

Skopec, L., Musco, T. and Sommers, B.D., 2014, July. A potential new data source for assessing the impacts of health reform: evaluating the Gallup-Healthways Well-Being Index. In Healthcare (Vol. 2, No. 2, pp. 113-120). Elsevier.

Smith, J.C. and C. Medalia. 2015. "Health Insurance Coverage in the United States: 2014.” 2015. Current Population Reports, P60-253.

Solon, G. 1985. "Work Incentive Effects of Taxing Unemployment Benefits." Econometrica 53: 295-306. Miller, S. and Wherry, L.R., 2017. "Health and Access to Care During the First 2 Years of the ACA Medicaid Expansions," New England Journal of Medicine, 376 (10): 947-956.

Sommers, B.D., Buchmueller, T., Decker, S.L., Carey, C. and Kronick, R., 2013. "The Affordable Care Act Has Led to Significant Gains in Health Insurance and Access to Care for Young Adults," Health Affairs, 32(1): 165-174.

Sommers, B.D., Gunja, M.Z., Finegold, K. and others. 2015. "Changes in Self-Reported Insurance Coverage, Access to Care and Health Under the Affordable Care Act," JAMA, 314(4): 366-374.

Sommers, B.D., Kenney, G.M. and Epstein, A.M. 2014. New evidence on the Affordable Care Act: coverage impacts of early Medicaid expansions. Health Affairs, 33(1), pp.78-87.

Sommers, B.D., Goldman, A.L., Blendon, R.J., Orav, E.J., and Epstein, A.M. 2019. "Medicaid Work Requirements-Results from the First Year in Arkansas," New England Journal of Medicine, 381(11): 1073-1082.

Sullivan, D. and Von Wachter, T., 2009. Job displacement and mortality: An analysis using administrative data. The Quarterly Journal of Economics, 124(3), pp.1265-1306.

Sullivan, J.X., 2008. Borrowing during unemployment unsecured debt as a safety net. Journal of Human Resources, 43(2), pp.383-412.

Valletta, R.G. 2014. "Recent Extensions of U.S. Unemployment Benefits: Search Responses in Alternative Labor Market States." IZA Journal of Labor Policy, 3, pp. 1-25.

Wherry, L.R. and Miller, S., 2016. Early Coverage, Access, Utilization, and Health Effects Associated With the Affordable Care Act Medicaid Expansions: A Quasi-experimental Study. Annals of Internal Medicine, 164(12), pp.795-803.

Wooldridge, J.M. 2002. Econometric Analysis of Cross Section and Panel Data. Cambridge, MA: MIT Press. 


\section{Figure 1}

Trends in insurance coverage by employment status, in states that did and did not expand Medicaid under the ACA

\section{Insurance coverage, by employment and state Medicaid status}

American Community Survey
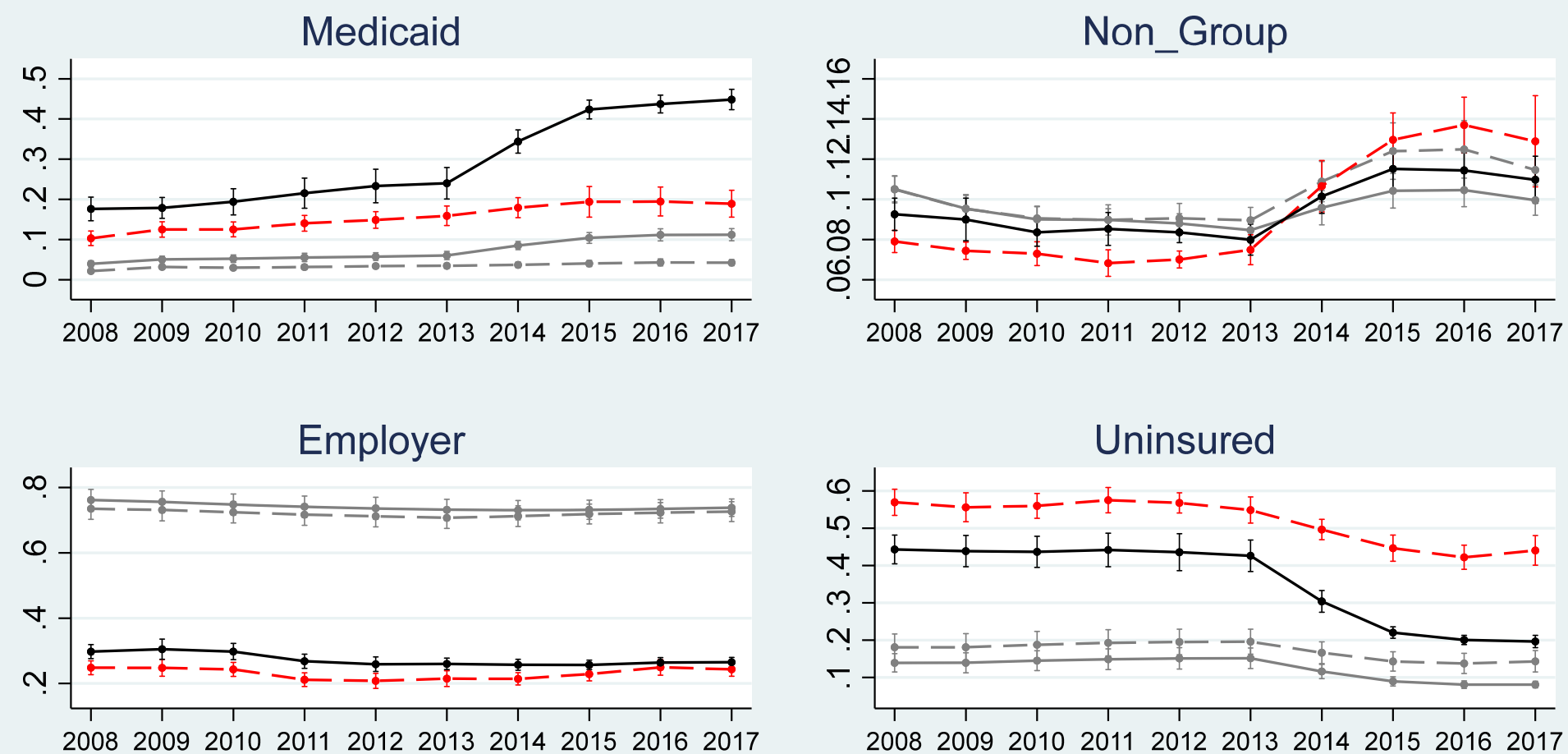

$$
\begin{array}{lll}
--\bullet-- \text { Employed, Non-expansion } & \text { Employed, Expansion } \\
--\bullet-- \text { Unemployed, Non-expansion } \quad \longrightarrow \text { Unemployed, Expansion }
\end{array}
$$

\section{Unemployed, Expansion}

Note: Estimated from annual ACS data on individuals ages 26-64 who are in the labor force. States that expanded Medicaid after 2014 are excluded. Vertical line segments show $95 \%$ confidence intervals for annual differences. 
Figure 2: Event history results for insurance coverage outcomes: Unemployed adults

\section{Insurance Coverage Event History Results (adjusted)}

Unemployed Adults ages 26-64
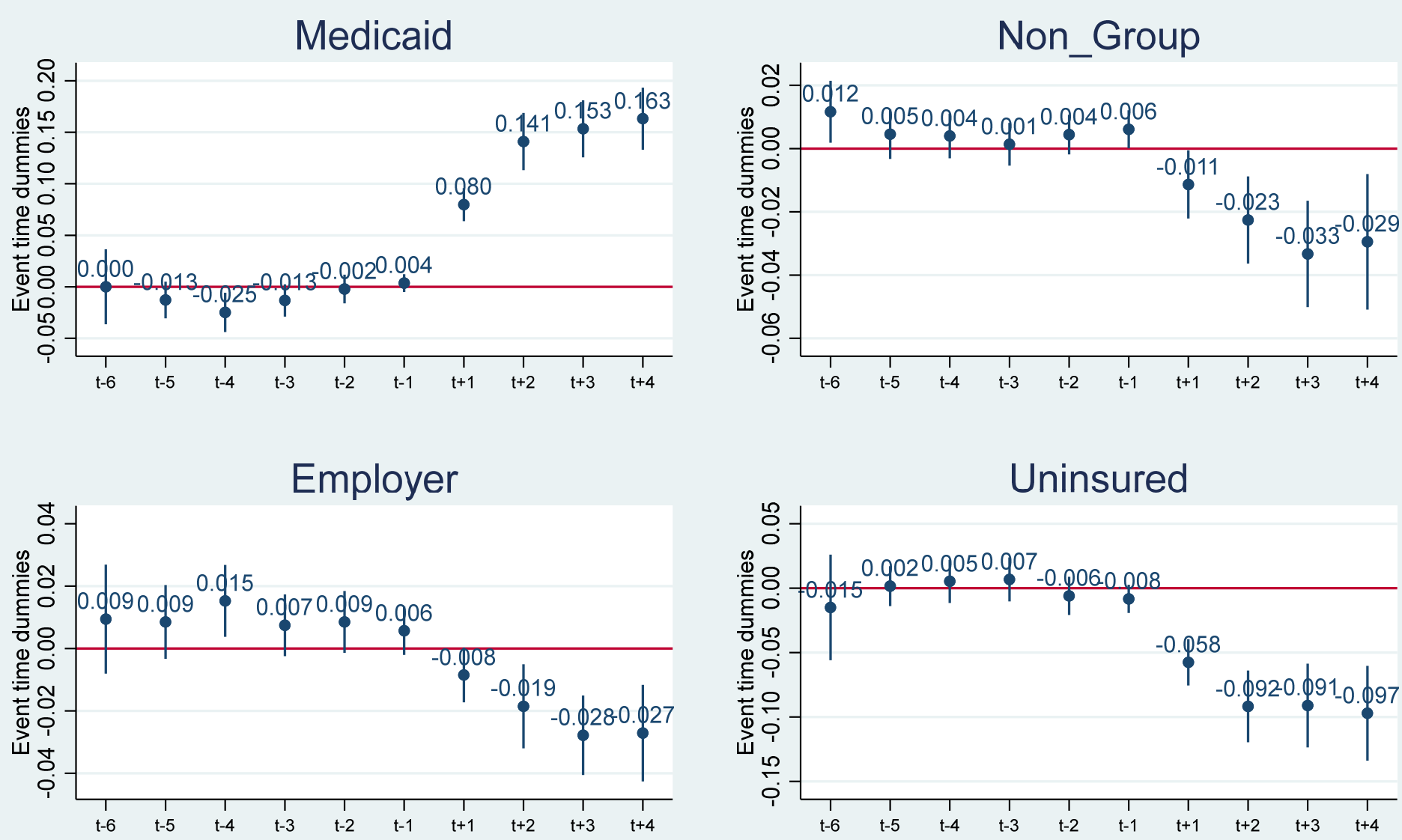

Note: From regressions using annual ACS data on individuals ages 26-64 who are unemployed. Time=0, corresponding to the calendar year just before the implementation of Medicaid expansion, is omitted. Vertical line segments show $95 \%$ confidence intervals for annual differences. 


\section{Figure 3}

Trends in insurance coverage by employment status, in states that did and did not expand Medicaid under the ACA

\section{Access to care, by employment and state Medicaid status Behavioral Risk Factor Surveillance Survey}
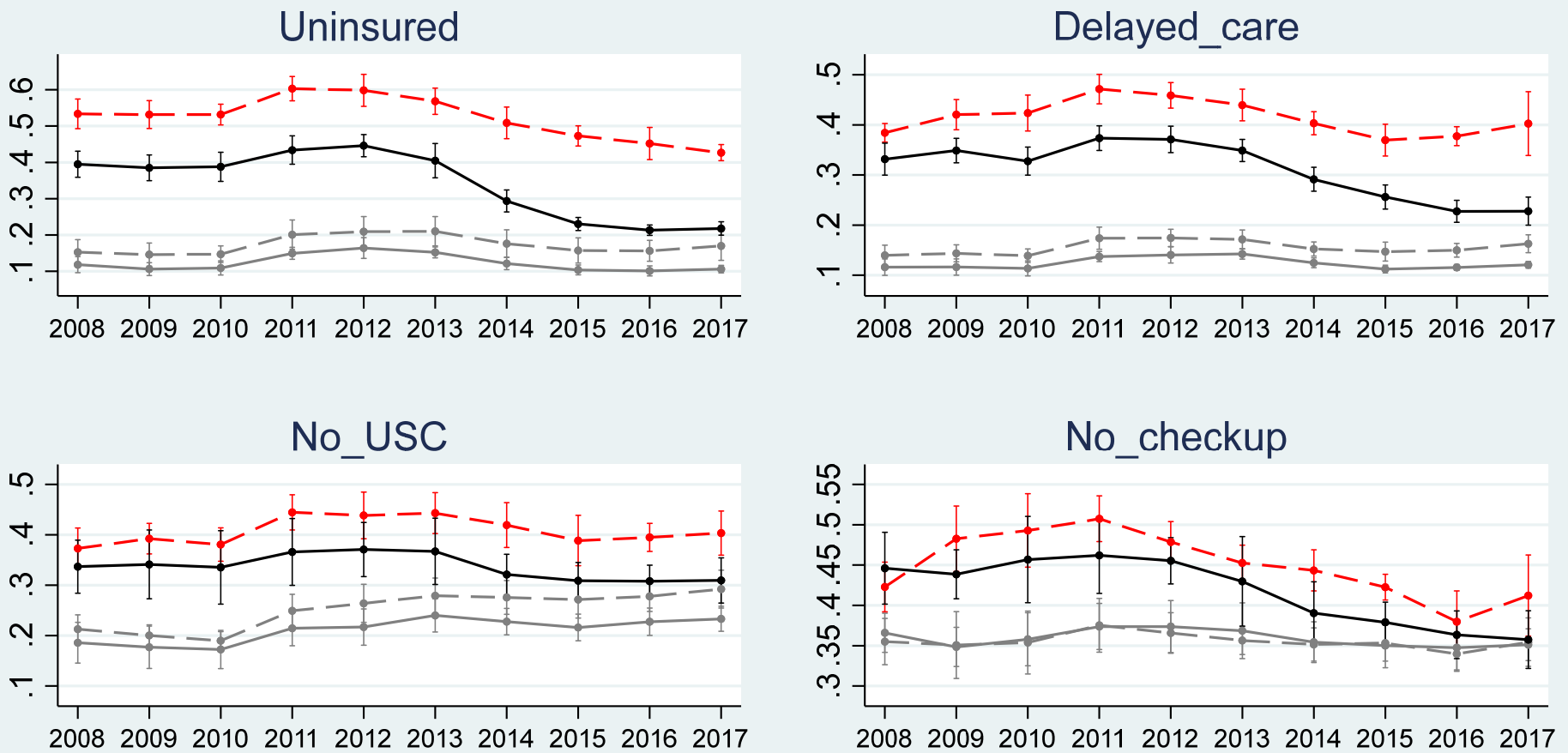

$$
\begin{array}{|lll}
\hline--\bullet-- \text { Employed, Non-expansion } & \cdots & \text { Employed, Expansion } \\
--\bullet-- \text { Unemployed, Non-expansion } \quad \longrightarrow \text { Unemployed, Expansion }
\end{array}
$$

Note: Estimated from annual BRFSS data on individuals ages 26-64 who are in the labor force. States that expanded Medicaid after 2014 are excluded. Vertical line segments show $95 \%$ confidence intervals. 
Figure 4: Event history results for access to care outcomes: Unemployed adults

\section{Insurance Coverage Event History Results (adjusted)}

Unemployed Adults ages 26-64
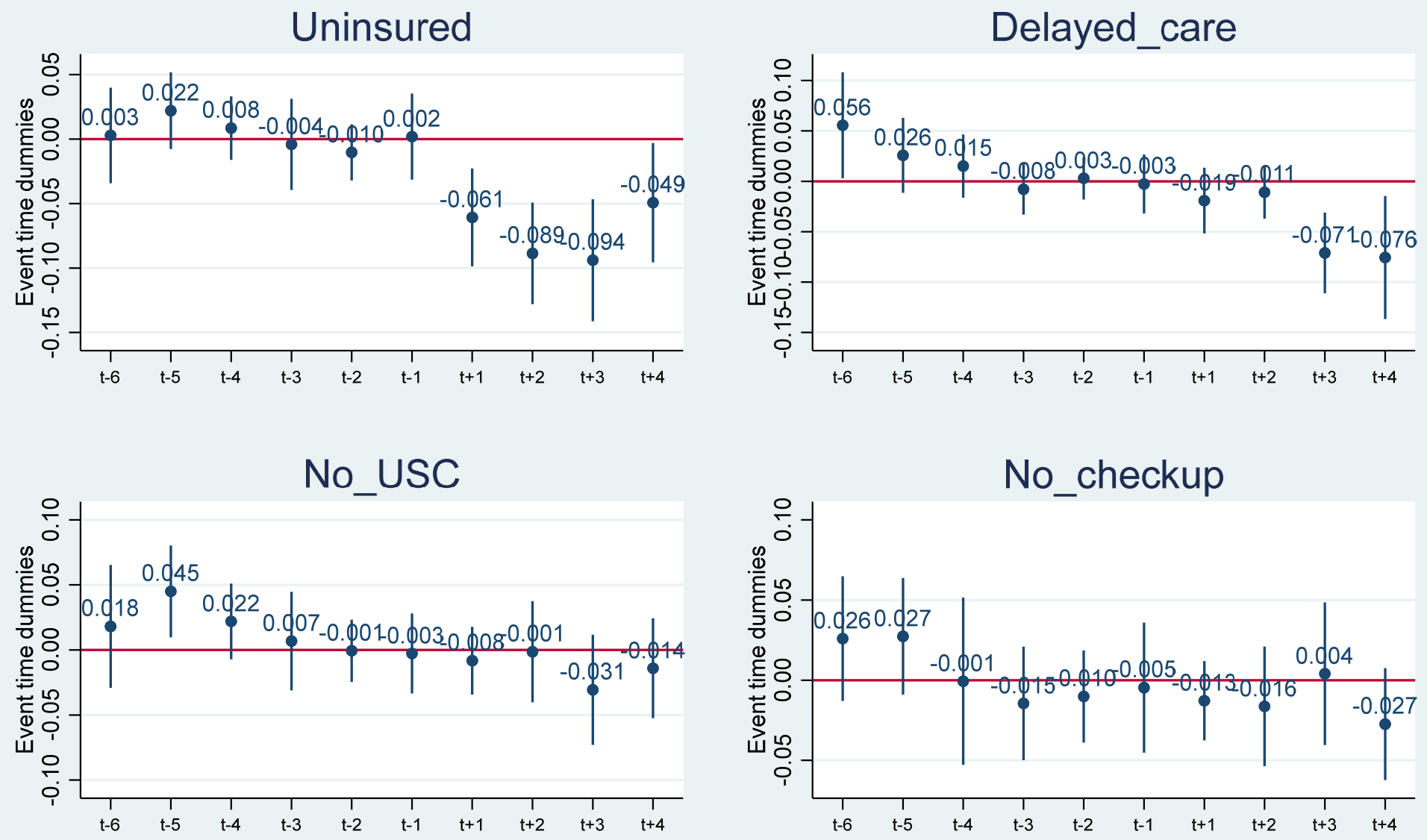

Note: From regressions using annual BRFSS data on individuals ages $26-64$ who are unemployed. Time $=0$, corresponding to the calendar year just before the implementation of Medicaid expansion, is omitted. Vertical line segments show $95 \%$ confidence intervals for annual differences. 


\section{Figure 5}

\section{Unemployment rates and UI availability}

(by Medicaid expansion status in January 2014)
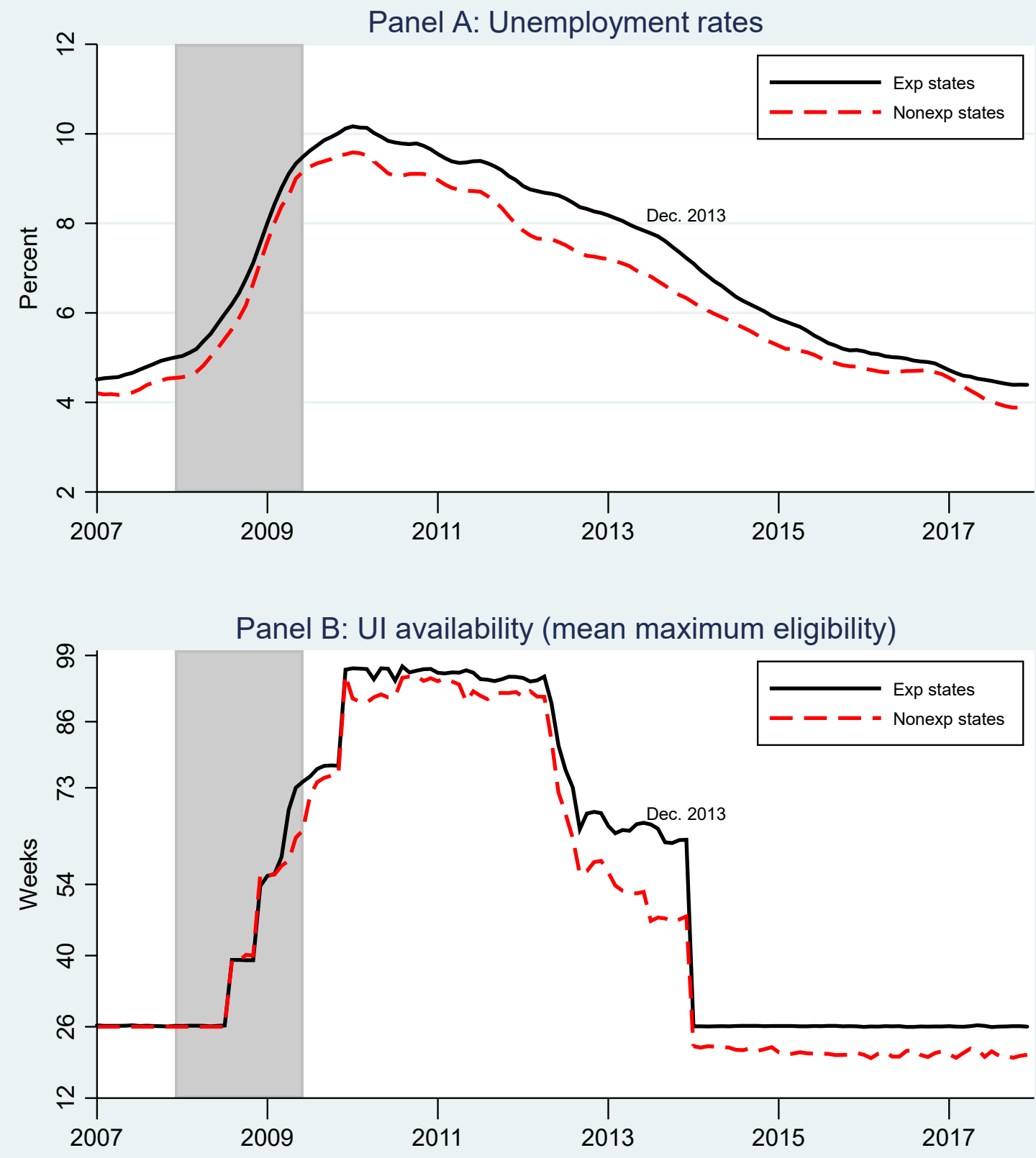

Note: Authors' calculations from BLS data in Panel A, CPS data in Panel B (unemployed excl. new entrants, weighted), merged with U.S. DOL data on UI availability and Kaiser Family Foundation data on Medicaid expansion status (states that expanded after January 2014 are excluded). Temporary suspensions of extended UI programs (Apr, Jun/Jul, and Dec 2010) ignored. Gray areas denote NBER recession dates. 
Figure 6

Unemployment Exit Rates (unadjusted) Medicaid Expansion (2014 only) vs. Non-expansion States

To employment

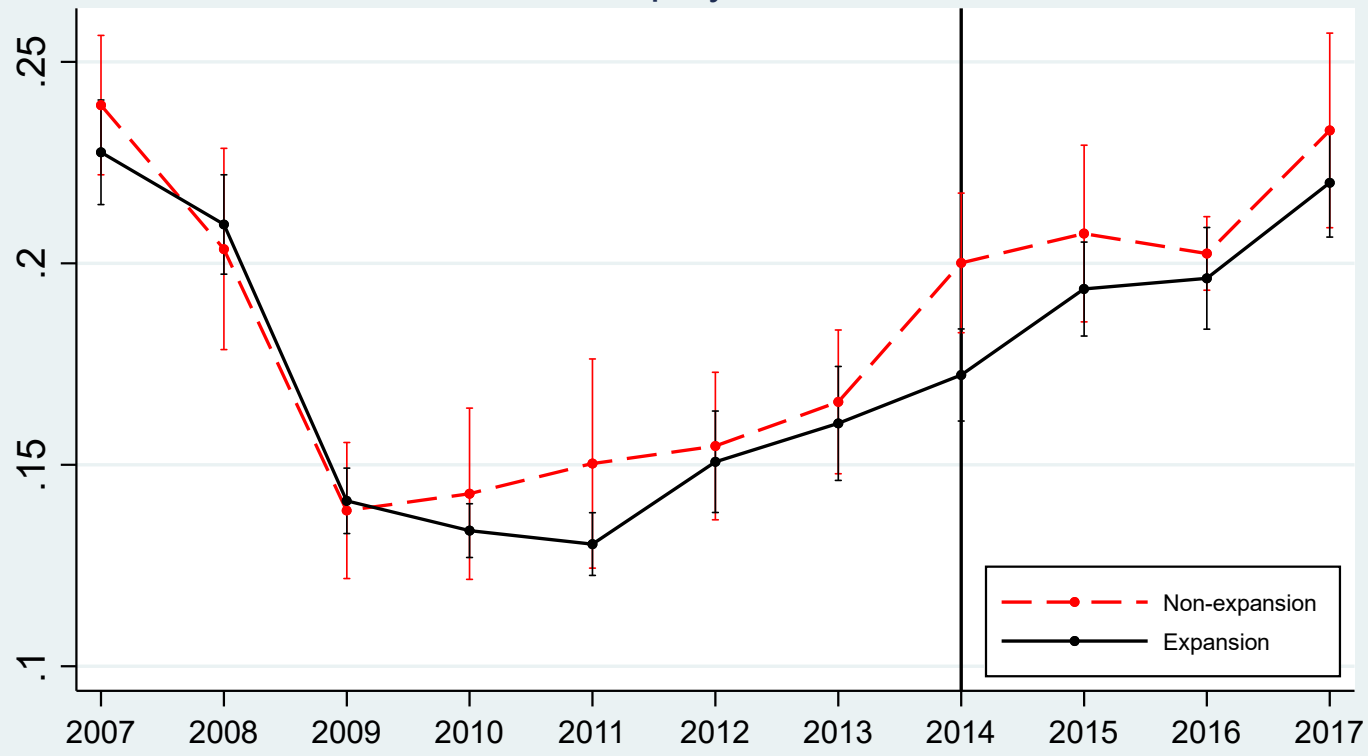

To NILF

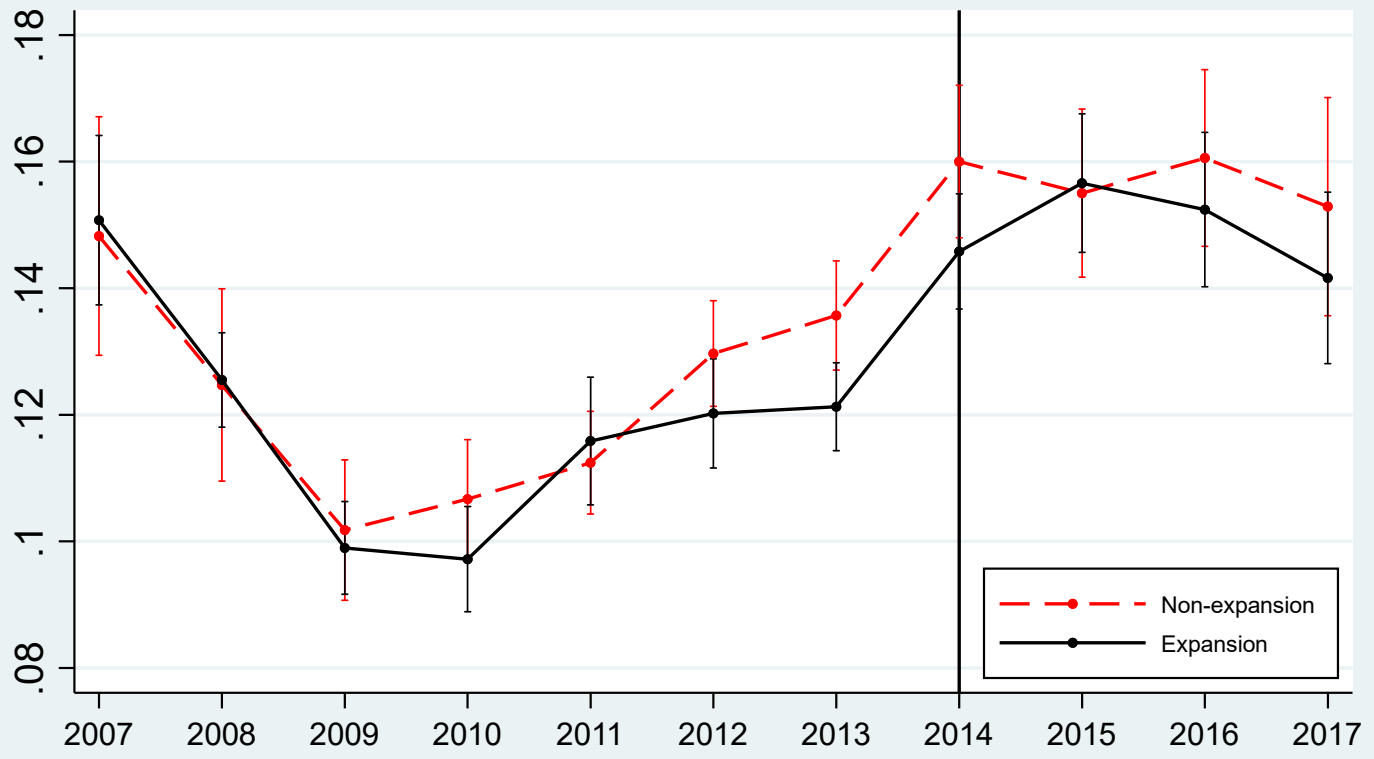

Note: Estimated from monthly CPS data on unemployed individuals ages 26-64, matched across months (corrected for UNU \& UEU transitions). States that expanded Medicaid after 2014 are excluded. Vertical line segments show $95 \%$ confidence intervals for annual differences. 
Figure 7

Unemployment Exit Rates (adjusted): All (ages 26-64)

All Medicaid Expansion vs. Non-expansion States
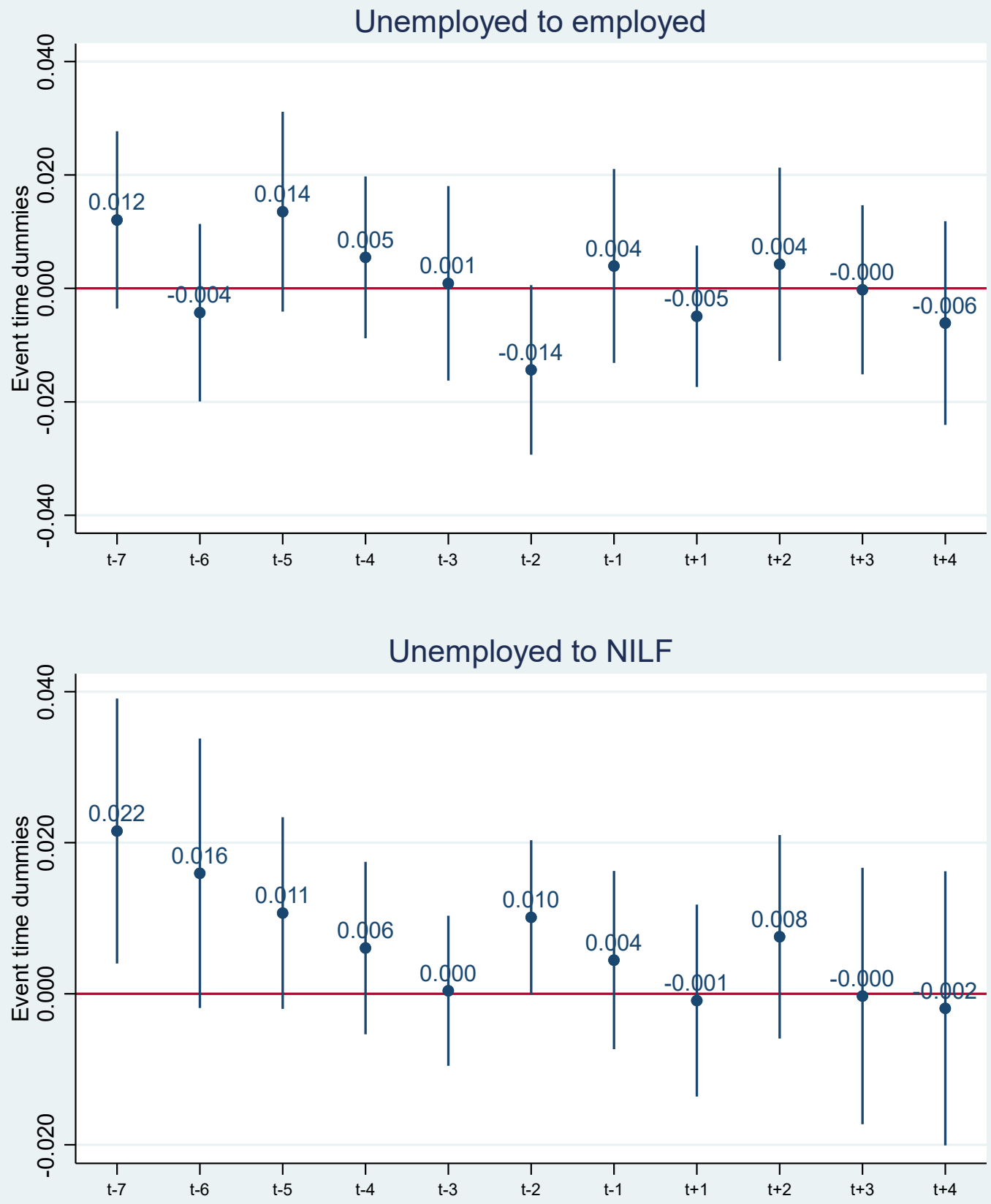

Note: From regressions using monthly CPS data on unemployed individuals ages 26-64, matched across months (corrected for UNU \& UEU transitions). Time $=0$, corresponding to the calendar year just before implementation of Medicaid expansion, is omitted. Vertical lines show $95 \%$ confidence intervals for annual differences. 
Table 1: Summary of State Medicaid Expansion Decisions as of 1/1/2017 and UI Benefit Policy

\begin{tabular}{|c|c|c|}
\hline \multicolumn{2}{|c|}{ Expansion States } & \multirow[t]{2}{*}{ Non-Expansion States (19) } \\
\hline By January 2014 (25) & After January 2014 (7) & \\
\hline$\overline{\text { Arizona }}$ & 4/14: Michigan & Alabama \\
\hline Arkansas & 8/14: New Hampshire & Florida \\
\hline California* & 1/15: Pennsylvania & Georgia \\
\hline Colorado & 2/15: Indiana & Idaho \\
\hline Connecticut* & 9/15: Alaska & Kansas \\
\hline Delaware & 1/16: Montana & Maine \\
\hline District of Columbia* & 7/16: Louisiana & Mississippi \\
\hline Hawaii & & Missouri \\
\hline Illinois & & Nebraska \\
\hline Iowa & & North Carolina \\
\hline Kentucky & & Oklahoma \\
\hline Maryland & & South Carolina \\
\hline Massachusetts & & South Dakota \\
\hline Minnesota* & & Tennessee \\
\hline Nevada & & Texas \\
\hline New Jersey* & & Utah \\
\hline New Mexico & & Virginia \\
\hline New York & & Wisconsin \\
\hline North Dakota & & Wyoming \\
\hline \multicolumn{3}{|l|}{ Ohio } \\
\hline \multicolumn{3}{|l|}{ Oregon } \\
\hline \multicolumn{3}{|l|}{ Rhode Island } \\
\hline \multicolumn{3}{|l|}{ Vermont } \\
\hline \multicolumn{3}{|l|}{ Washington* } \\
\hline West Virginia & & \\
\hline
\end{tabular}

Mean possible Weeks of UI Benefits: Dec. 2013/Jan. 2014 $60.8 / 25.8$ $60.7 / 26.1$

Fraction of unemployed worker sample in each group $0.598 \quad 0.079$ 0.323

Notes: * denotes state began implementing Medicaid expansion before January 2014. Federal extended UI benefits expired in January 2014. Figures represent mean weeks for each category of states weighted by non-farm payroll employment in each state. 
Table 2: Percent Uninsured by Employment and State Medicaid Expansion Status, 2008-2010

\begin{tabular}{|c|c|c|c|c|c|c|}
\hline & \multicolumn{3}{|c|}{ Non-Expansion States } & \multicolumn{3}{|c|}{ Expansion States } \\
\hline & Employed & Unemployed & Difference & Employed & Unemployed & Difference \\
\hline All Adults 26-64 & 0.183 & 0.561 & 0.378 & 0.138 & 0.443 & 0.304 \\
\hline \multicolumn{7}{|l|}{ By Age } \\
\hline 26 to 39 & 0.241 & 0.613 & 0.372 & 0.186 & 0.499 & 0.312 \\
\hline 40 to 54 & 0.162 & 0.561 & 0.398 & 0.120 & 0.432 & 0.312 \\
\hline 55 to 64 & 0.112 & 0.415 & 0.303 & 0.084 & 0.324 & 0.240 \\
\hline \multicolumn{7}{|l|}{ By Education } \\
\hline Ed: HS or less & 0.110 & 0.461 & 0.351 & 0.084 & 0.365 & 0.281 \\
\hline Ed: More than HS & 0.312 & 0.646 & 0.334 & 0.244 & 0.520 & 0.276 \\
\hline \multicolumn{7}{|l|}{ By Race/Ethnicity } \\
\hline White non-Hispanic & 0.125 & 0.500 & 0.375 & 0.095 & 0.398 & 0.303 \\
\hline Black non-Hispanic & 0.201 & 0.594 & 0.393 & 0.156 & 0.462 & 0.306 \\
\hline Asian non-Hispanic & 0.187 & 0.457 & 0.270 & 0.128 & 0.403 & 0.276 \\
\hline Other non-Hispanic & 0.236 & 0.604 & 0.368 & 0.185 & 0.478 & 0.293 \\
\hline Hispanic (any race) & 0.434 & 0.733 & 0.299 & 0.335 & 0.576 & 0.241 \\
\hline \multicolumn{7}{|l|}{ By Gender } \\
\hline Women & 0.158 & 0.500 & 0.342 & 0.116 & 0.370 & 0.254 \\
\hline Men & 0.205 & 0.611 & 0.406 & 0.159 & 0.499 & 0.341 \\
\hline \multicolumn{7}{|l|}{ By Parental Status } \\
\hline Non-Parent & 0.182 & 0.596 & 0.414 & 0.141 & 0.490 & 0.349 \\
\hline Parent & 0.184 & 0.497 & 0.313 & 0.138 & 0.443 & 0.304 \\
\hline Sample n & $1,267,071$ & 90,231 & & $2,122,630$ & 162,950 & \\
\hline
\end{tabular}

Notes: Estimates are for employed and unemployed adults between the ages of 26 and 64 . Individuals not in the labor force are excluded. 
Table 3: Differences-in-Differences Estimates of the Effect of the ACA Medicaid Expansion on the Probability of Being Uninsured (ACS) All Expansion States vs. Non-Expansion States

\begin{tabular}{|c|c|c|c|c|c|c|c|}
\hline \multirow{2}{*}{\multicolumn{2}{|c|}{$\begin{array}{c} \\
\text { Full sample } \\
\end{array}$}} & \multicolumn{2}{|c|}{ Education } & \multicolumn{2}{|c|}{$\underline{\text { Parental status }}$} & \multicolumn{2}{|c|}{ When last worked } \\
\hline & & HS or less & $>\mathrm{HS}$ & Parent & Non-parent & $<1$ year & $\geq 1$ year \\
\hline \multicolumn{8}{|c|}{ A. Unemployed Adults } \\
\hline \multicolumn{8}{|l|}{ Dependent variable: } \\
\hline Uninsured & $\begin{array}{l}-0.080 * * * \\
(0.011)\end{array}$ & $\begin{array}{l}-0.109 * * * \\
(0.013)\end{array}$ & $\begin{array}{l}-0.056 * * * \\
(0.011)\end{array}$ & $\begin{array}{l}-0.030^{*} \\
(0.011)\end{array}$ & $\begin{array}{l}-0.105 * * * \\
(0.012)\end{array}$ & $\begin{array}{l}-0.076 * * * \\
(0.011)\end{array}$ & $\begin{array}{l}-0.085^{* * *} \\
(0.012)\end{array}$ \\
\hline Medicaid & $\begin{array}{l}0.133 * * * \\
(0.010)\end{array}$ & $\begin{array}{l}0.143 * * * \\
(0.013)\end{array}$ & $\begin{array}{l}0.126^{* * *} \\
(0.009)\end{array}$ & $\begin{array}{l}0.068 * * * \\
(0.009)\end{array}$ & $\begin{array}{l}0.163 * * * \\
(0.012)\end{array}$ & $\begin{array}{l}0.127 * * * \\
(0.010)\end{array}$ & $\begin{array}{l}0.141 * * * \\
(0.012)\end{array}$ \\
\hline Private non-group & $\begin{array}{l}-0.025 * * * \\
(0.006)\end{array}$ & $\begin{array}{l}-0.016^{*} \\
(0.006)\end{array}$ & $\begin{array}{l}-0.035 * * * \\
(0.006)\end{array}$ & $\begin{array}{l}-0.014^{*} \\
(0.007)\end{array}$ & $\begin{array}{l}-0.030 * * * \\
(0.006)\end{array}$ & $\begin{array}{l}-0.024 * * * \\
(0.006)\end{array}$ & $\begin{array}{l}-0.027 * * * \\
(0.006)\end{array}$ \\
\hline Employer & $\begin{array}{l}-0.025 * * * \\
(0.005)\end{array}$ & $\begin{array}{l}-0.017 * * * \\
(0.005)\end{array}$ & $\begin{array}{l}-0.032 * * * \\
(0.007)\end{array}$ & $\begin{array}{l}-0.028 * * * \\
(0.007)\end{array}$ & $\begin{array}{l}-0.023 * * * \\
(0.005)\end{array}$ & $\begin{array}{l}-0.028 * * * \\
(0.007)\end{array}$ & $\begin{array}{l}-0.023 * * * \\
(0.005)\end{array}$ \\
\hline $\mathrm{N}$ & 739,821 & 357,447 & 382,374 & 247,479 & 480,240 & 413,86 & 328,435 \\
\hline \multicolumn{8}{|l|}{ B. Employed Adults } \\
\hline \multicolumn{8}{|l|}{ Dependent variable: } \\
\hline Uninsured & $\begin{array}{l}-0.008 \\
(0.006)\end{array}$ & $\begin{array}{l}-0.021 * \\
(0.009)\end{array}$ & $\begin{array}{l}-0.003 \\
(0.004)\end{array}$ & $\begin{array}{l}-0.005 \\
(0.006)\end{array}$ & $\begin{array}{l}-0.009 \\
(0.006)\end{array}$ & & \\
\hline Medicaid & $\begin{array}{l}0.035 * * * \\
(0.003)\end{array}$ & $\begin{array}{l}0.058^{* * *} \\
(0.006)\end{array}$ & $\begin{array}{l}0.025^{* * *} \\
(0.002)\end{array}$ & $\begin{array}{l}0.036^{* * *} \\
(0.004)\end{array}$ & $\begin{array}{l}0.035 * * * \\
(0.003)\end{array}$ & & \\
\hline Private non-group & $\begin{array}{l}-0.015^{* * *} \\
(0.004)\end{array}$ & $\begin{array}{l}-0.019 * * \\
(0.006)\end{array}$ & $\begin{array}{l}-0.012 * * * \\
(0.003)\end{array}$ & $\begin{array}{l}-0.015^{* * *} \\
(0.004)\end{array}$ & $\begin{array}{l}-0.015 * * * \\
(0.004)\end{array}$ & & \\
\hline Employer & $\begin{array}{l}-0.011^{*} \\
(0.004)\end{array}$ & $\begin{array}{l}-0.018^{* *} \\
(0.006)\end{array}$ & $\begin{array}{l}-0.008^{*} \\
(0.003)\end{array}$ & $\begin{array}{l}-0.015^{* *} \\
(0.005)\end{array}$ & $\begin{array}{l}-0.009 \\
(0.004)\end{array}$ & & \\
\hline $\mathrm{N}$ & $11,298,996$ & $3,619,312$ & $7,679,684$ & $4,372,618$ & $6,885,983$ & & \\
\hline
\end{tabular}

Notes: ${ }^{* * *} \mathrm{p}<0.001 ;{ }^{* *} \mathrm{p}<0.01 ;{ }^{*} \mathrm{p}<0.05$ 
Table 4: Differences-in-Differences Estimates of the Effect of the ACA Medicaid Expansion on Access to Care (BRFSS) All Expansion States vs. Non-Expansion States

\begin{tabular}{|c|c|c|c|c|c|c|c|c|}
\hline & \multirow[b]{2}{*}{ Full Sample } & \multicolumn{2}{|c|}{$\underline{\text { Education }}$} & \multicolumn{2}{|c|}{$\underline{\text { Parental status }}$} & \multicolumn{2}{|c|}{ When last worked } & \multirow{2}{*}{$\begin{array}{l}\text { Health is } \\
\text { fair/poor }\end{array}$} \\
\hline & & HS or less & $>\mathrm{HS}$ & Parent & Non-Parent & $<1$ year & $\geq 1$ year & \\
\hline \multicolumn{9}{|l|}{ A. Unemployed Adults } \\
\hline \multicolumn{9}{|l|}{ Dependent variable: } \\
\hline \multirow[t]{2}{*}{ Uninsured } & $-0.075 * * *$ & $-0.077 * * *$ & $-0.073 * * *$ & -0.022 & $-0.116 * * *$ & $-0.068 * * *$ & $-0.082 * * *$ & $-0.108 * * *$ \\
\hline & $(0.014)$ & $(0.016)$ & $(0.014)$ & $(0.014)$ & $(0.019)$ & $(0.017)$ & $(0.018)$ & $(0.023)$ \\
\hline Delayed Care & $\begin{array}{l}-0.043^{* * *} \\
(0.009)\end{array}$ & $\begin{array}{l}-0.054^{* * *} \\
(0.012)\end{array}$ & $\begin{array}{l}-0.031 * * \\
(0.011)\end{array}$ & $\begin{array}{l}-0.015 \\
(0.014)\end{array}$ & $\begin{array}{l}-0.067 * * * \\
(0.011)\end{array}$ & $\begin{array}{l}-0.030 * * \\
(0.010)\end{array}$ & $\begin{array}{l}-0.057 * * * \\
(0.012)\end{array}$ & $\begin{array}{l}-0.091 * * * \\
(0.015)\end{array}$ \\
\hline No usual source of care & $\begin{array}{l}-0.022 * \\
(0.008)\end{array}$ & $\begin{array}{l}-0.022 * \\
(0.011)\end{array}$ & $\begin{array}{l}-0.019 \\
(0.010)\end{array}$ & $\begin{array}{l}-0.017 \\
(0.009)\end{array}$ & $\begin{array}{l}-0.027^{*} \\
(0.012)\end{array}$ & $\begin{array}{l}-0.010 \\
(0.008)\end{array}$ & $\begin{array}{l}-0.034 \\
(0.019)\end{array}$ & $\begin{array}{l}-0.024 \\
(0.020)\end{array}$ \\
\hline No checkup in past year & $\begin{array}{l}-0.011 \\
(0.010)\end{array}$ & $\begin{array}{l}-0.009 \\
(0.015)\end{array}$ & $\begin{array}{l}-0.014 \\
(0.009)\end{array}$ & $\begin{array}{l}-0.006 \\
(0.014)\end{array}$ & $\begin{array}{l}-0.016 \\
(0.010)\end{array}$ & $\begin{array}{l}-0.007 \\
(0.012)\end{array}$ & $\begin{array}{l}-0.016 \\
(0.012)\end{array}$ & $\begin{array}{l}-0.017 \\
(0.016)\end{array}$ \\
\hline $\mathrm{N}$ & 175,295 & 80,718 & 94,257 & 64,051 & 111,244 & 85,216 & 90,079 & 46,233 \\
\hline \multicolumn{9}{|l|}{ B. Employed Adults } \\
\hline \multicolumn{9}{|l|}{ Dependent variable: } \\
\hline Uninsured & $\begin{array}{l}-0.008 * \\
(0.004)\end{array}$ & $\begin{array}{l}-0.009 \\
(0.007)\end{array}$ & $\begin{array}{l}-0.007 * \\
(0.003)\end{array}$ & $\begin{array}{l}-0.007 \\
(0.005)\end{array}$ & $\begin{array}{l}-0.010 * * \\
(0.003)\end{array}$ & & & $\begin{array}{l}-0.014 \\
(0.012)\end{array}$ \\
\hline Delayed Care & $\begin{array}{l}-0.002 \\
(0.003)\end{array}$ & $\begin{array}{l}-0.005 \\
(0.003)\end{array}$ & $\begin{array}{l}-0.001 \\
(0.004)\end{array}$ & $\begin{array}{l}-0.001 \\
(0.004)\end{array}$ & $\begin{array}{l}-0.003 \\
(0.003)\end{array}$ & & & $\begin{array}{l}-0.004 \\
(0.010)\end{array}$ \\
\hline No usual source of care & $\begin{array}{l}-0.017 * * \\
(0.006)\end{array}$ & $\begin{array}{l}-0.025 * * \\
(0.009)\end{array}$ & $\begin{array}{l}-0.011 * \\
(0.005)\end{array}$ & $\begin{array}{l}-0.017 * \\
(0.007)\end{array}$ & $\begin{array}{l}-0.017 * \\
(0.007)\end{array}$ & & & $\begin{array}{l}-0.031 * \\
(0.012)\end{array}$ \\
\hline No checkup in past year & $\begin{array}{l}-0.004 \\
(0.007)\end{array}$ & $\begin{array}{l}-0.006 \\
(0.008)\end{array}$ & $\begin{array}{l}-0.002 \\
(0.007)\end{array}$ & $\begin{array}{l}-0.001 \\
(0.009)\end{array}$ & $\begin{array}{l}-0.007 \\
(0.006)\end{array}$ & & & $\begin{array}{l}-0.011 \\
(0.013)\end{array}$ \\
\hline $\mathrm{N}$ & $1,864,865$ & 523,909 & $1,337,908$ & 781,249 & $1,083,616$ & & & 167,982 \\
\hline
\end{tabular}

Notes: *** $\mathrm{p}<0.001 ; * * \mathrm{p}<0.01 ; * \mathrm{p}<0.05$ 
Table 5: Differences-in-Differences Estimates of the Effect of the ACA Medicaid Expansion on Unemployment Exits (CPS)

\begin{tabular}{|c|c|c|c|c|c|c|c|}
\hline & \multirow[b]{2}{*}{ Full sample } & \multicolumn{2}{|c|}{$\underline{\text { Education }}$} & \multicolumn{2}{|c|}{$\underline{\text { Parental status }}$} & \multicolumn{2}{|c|}{$\begin{array}{c}\text { Duration of } \\
\text { unemployment }\end{array}$} \\
\hline & & HS or less & $>\mathrm{HS}$ & Parent & Non-Parent & $<1$ year & $\geq 1$ year \\
\hline \multicolumn{8}{|l|}{ Dependent Variable } \\
\hline Exit to employment & $\begin{array}{l}-0.0023 \\
(0.0037)\end{array}$ & $\begin{array}{c}0.0030 \\
(0.0041)\end{array}$ & $\begin{array}{l}-0.0072 \\
(0.0062)\end{array}$ & $\begin{array}{c}0.0006 \\
(0.0075)\end{array}$ & $\begin{array}{l}-0.0040 \\
(0.0063)\end{array}$ & $\begin{array}{l}-0.0033 \\
(0.0048)\end{array}$ & $\begin{array}{l}-0.0009 \\
(0.0073)\end{array}$ \\
\hline Exit to NILF & $\begin{array}{l}-0.0043 \\
(0.0050)\end{array}$ & $\begin{array}{l}-0.0060 \\
(0.0071)\end{array}$ & $\begin{array}{l}-0.0022 \\
(0.0057)\end{array}$ & $\begin{array}{l}-0.0163 * \\
(0.0071)\end{array}$ & $\begin{array}{c}0.0025 \\
(0.0073)\end{array}$ & $\begin{array}{l}-0.0116^{*} \\
(0.0051)\end{array}$ & $\begin{array}{c}0.0210 \\
(0.0111)\end{array}$ \\
\hline $\mathrm{N}$ & 166838 & 83095 & 83743 & 61069 & 105769 & 124912 & 41926 \\
\hline
\end{tabular}


Table 6: Robustness checks

Alternate definitions of expansion states

\begin{tabular}{|c|c|c|c|}
\hline & $\begin{array}{l}\text { All expanders vs } \\
\text { non-expanders }\end{array}$ & $\begin{array}{c}2014,2015 \& 2016 \\
\text { expanders vs non-expanders }\end{array}$ & $\begin{array}{l}2015 \& 2016 \text { expanders } \\
\text { Vs non-expanders }\end{array}$ \\
\hline & $(1)$ & (2) & (3) \\
\hline \multicolumn{4}{|c|}{ A. Insurance coverage outcomes (ACS) } \\
\hline Uninsured & $\begin{array}{l}-0.080 * * * \\
(0.011)\end{array}$ & $\begin{array}{l}-0.078 * * * \\
(0.014)\end{array}$ & $\begin{array}{l}-0.068 * * * \\
(0.009)\end{array}$ \\
\hline Medicaid & $\begin{array}{l}0.133^{* * *} \\
(0.010)\end{array}$ & $\begin{array}{l}0.134 * * * \\
(0.013)\end{array}$ & $\begin{array}{l}0.118^{* * *} \\
(0.011)\end{array}$ \\
\hline Private non-group & $\begin{array}{l}-0.025^{* * *} \\
(0.006)\end{array}$ & $\begin{array}{l}-0.025^{* * *} \\
(0.006)\end{array}$ & $\begin{array}{l}-0.020^{* * *} \\
(0.005)\end{array}$ \\
\hline Employer & $\begin{array}{l}-0.025 * * * \\
(0.005)\end{array}$ & $\begin{array}{l}-0.029 * * * \\
(0.005)\end{array}$ & $\begin{array}{l}-0.029 * * * \\
(0.006)\end{array}$ \\
\hline $\mathrm{N}$ & 739,821 & 569,867 & 348,827 \\
\hline \multicolumn{4}{|c|}{ B. Access to care outcomes (BRFSS) } \\
\hline Uninsured & $\begin{array}{l}-0.075^{* * *} \\
(0.014)\end{array}$ & $\begin{array}{l}-0.084^{* * *} \\
(0.019)\end{array}$ & $\begin{array}{l}-0.100 * * * \\
(0.013)\end{array}$ \\
\hline Delayed care & $\begin{array}{l}-0.043 * * * \\
(0.009)\end{array}$ & $\begin{array}{l}-0.038^{* * *} \\
(0.010)\end{array}$ & $\begin{array}{l}-0.022 \\
(0.012)\end{array}$ \\
\hline $\begin{array}{l}\text { No usual } \\
\text { source of care }\end{array}$ & $\begin{array}{l}-0.022^{*} \\
(0.008)\end{array}$ & $\begin{array}{l}-0.014 \\
(0.008)\end{array}$ & $\begin{array}{l}-0.016 \\
(0.012)\end{array}$ \\
\hline $\begin{array}{l}\text { No checkup } \\
\text { in past } 12 \text { months }\end{array}$ & $\begin{array}{l}-0.011 \\
(0.010)\end{array}$ & $\begin{array}{l}-0.012 \\
(0.011)\end{array}$ & $\begin{array}{l}-0.013 \\
(0.015)\end{array}$ \\
\hline $\mathrm{N}$ & 175,295 & 143,958 & 85,817 \\
\hline \multicolumn{4}{|c|}{ C. Transitions out of unemployment (CPS) } \\
\hline Exits to employment & $\begin{array}{l}-0.0023 \\
(0.0037)\end{array}$ & $\begin{array}{l}-0.0010 \\
(0.0038)\end{array}$ & $\begin{array}{l}0.0078 \\
(0.0055)\end{array}$ \\
\hline Exits to NILF & $\begin{array}{l}-0.0043 \\
(0.0050)\end{array}$ & $\begin{array}{l}-0.0044 \\
(0.0058)\end{array}$ & $\begin{array}{l}-0.0095 \\
(0.0121)\end{array}$ \\
\hline $\mathrm{N}$ & 166,849 & 120,933 & 75,248 \\
\hline
\end{tabular}

